\title{
Influence of particle size and shape on the backscattering linear depolarisation ratio of small ice crystals - cloud chamber measurements in the context of contrail and cirrus microphysics
}

\author{
M. Schnaiter, S. Büttner, O. Möhler, J. Skrotzki, M. Vragel, and R. Wagner \\ Karlsruhe Institute of Technology, Institute for Meteorology and Climate Research, P.O. Box 3640, \\ 76021 Karlsruhe, Germany \\ Correspondence to: M. Schnaiter (martin.schnaiter@kit.edu)
}

Received: 31 May 2012 - Published in Atmos. Chem. Phys. Discuss.: 18 June 2012

Revised: 28 October 2012 - Accepted: 30 October 2012 - Published: 9 November 2012

\begin{abstract}
The article presents the laser scattering and depolarisation instrument SIMONE that is installed at the large aerosol and cloud chamber facility AIDA of the Karlsruhe Institute of Technology. SIMONE uses a $488 \mathrm{~nm} \mathrm{cw}$ laser to probe simulated atmospheric clouds by measuring the scattered light from the $1.8^{\circ}$ and $178.2^{\circ}$ directions. At $178.2^{\circ}$, the scattered light is analysed for the linear polarisation state to deduce the particle linear depolarisation ratio $\delta_{\mathrm{p}}$ which is a common measurement parameter of atmospheric lidar applications. The optical setup and the mathematical formalism of the depolarisation detection concept are given. SIMONE depolarisation measurements in spheroidal hematite aerosol and supercooled liquid clouds are used to validate the instrument.

SIMONE data from a series of AIDA ice nucleation experiments at temperatures between 195 and $225 \mathrm{~K}$ were analysed in terms of the impact of the ice particle microphysics on $\delta_{\mathrm{p}}$. We found strong depolarisation values of up to 0.4 in case of small growing and sublimating ice particles with volume equivalent diameters of only a few micrometers.

Modelling runs with the T-matrix method showed that the measured depolarisation ratios can be accurately reproduced assuming spheroidal and cylindrical particles with a size distribution that has been constrained by IR extinction spectroscopy. Based on the T-matrix modelling runs, we demonstrate that in case of small ice crystals the SIMONE depolarisation results are representative for the lidar depolarisation ratio which is measured at exact backscattering direction of $180^{\circ}$.
\end{abstract}

The relevance of our results for the interpretation of recent lidar observations in cirrus and contrails is discussed. In view of our results, the high depolarisation ratios observed by the spaceborne lidar CALIOP in the tropical upper troposphere might be a hint for the presence of small (sublimating) ice particles in the outflows of deep convective systems.

\section{Introduction}

The importance of small ice crystals $(<50 \mu \mathrm{m})$ for cirrus cloud radiative properties is a matter of controversial debate, mainly because some measurements seemed to clearly overestimate the number concentrations of small ice particles due to particle shattering on the instrument inlets (Field et al., 2006; McFarquhar et al., 2007; Jensen et al., 2009; Lawson, 2011; Korolev et al., 2011). Yet, if present, small ice crystals are important for the radiative properties of these clouds (Garrett et al., 2003). Two recent studies by Cooper and Garrett $(2010,2011)$ used remote sensing observations by the MODIS satellite as an independent method to constrain the frequency of thin cirrus clouds composed of small ice particles with an effective radius below $20 \mu \mathrm{m}$. A very conservative assessment of their data resulted in a minimum fraction of globally 15-20\% for such clouds. This value was even increased to $35 \%$ when the analysis was restricted to thin cirrus clouds observed in the tropics, with temperatures below $220 \mathrm{~K}$. 
There is no doubt that small micrometer-sized ice crystals dominate the particle size distributions of aircraft condensation trails (contrails) and young cirrus (Schröder et al., 2000; Voigt et al., 2010). Small ice crystals are nucleated immediately in the moisty particulate emissions of aircraft engines if the ambient temperature is cold enough. This results in the formation of line-shaped visible ice clouds, socalled contrails. Under ambient ice supersaturated humidity conditions, the contrails do not dissipate as under dry conditions but persist and spread out to form more extended cirrus clouds. In this way, an aviation-induced cloudiness, i.e. contrail cirrus, is added to the natural cirrus field. Whereas the mean global climate impact of persistent line-shaped contrails tends to be weak, the impact of contrail cirrus and other aviation-induced cirrus is still rather unknown. However, Mannstein and Schumann (2005) concluded from a direct correlation of satellite observations of cirrus cloud cover with aviation flight density data that the radiative effect of aviation-induced cirrus clouds may be more than 10 times larger than the effect of line-shaped contrails. In their analysis, the observed increase of cirrus coverage with air traffic density is mainly attributed to spreading contrails, i.e. contrail cirrus. A similar conclusion, but on a global scale, was drawn by Burkhardt and Kärcher (2011) based on results of a global climate model that was extended by a contrail cirrus module to simulate the life cycle of this anthropogenic cloud type.

The polarisation Light Detection and Ranging (lidar) technique is widely used to investigate the microphysical properties of cirrus clouds and contrails remotely. With the CloudAerosol lidar with Orthogonal Polarisation (CALIOP) onboard the CALIPSO satellite, these depolarisation data are now available on a global scale. A recent global survey of CALIPSO particle linear depolarisation ratios $\delta_{\mathrm{p}}$ for tropospheric ice clouds by Sassen and Zhu (2009) has revealed depolarisation ratios that (i) increase with increasing height/decreasing temperature and (ii) tend to decrease with increasing latitude. Maximum depolarisation values up to 0.4 and between 0.45 and 0.55 were found in tropical upper tropospheric clouds and in orographically driven lower stratospheric "nacreous" clouds at high latitudes, respectively. In a more recent study, Martins et al. (2011) have evaluated $2.5 \mathrm{yr}$ of CALIOP measurements, yielding average depolarisation ratios of tropical cirrus and subvisible cirrus of $0.43 \pm 0.08$ and $0.41 \pm 0.08$, respectively. Similar to the results by Sassen and Zhu (2009), they also found that the depolarisation ratios in the midlatidudes are in general about 0.08 lower than in the tropics. Ground-based polarisation lidar is also frequently used to investigate the microphysics of contrails and contrail cirrus remotely (Freudenthaler et al., 1996; Sassen and Hsueh, 1998; Sussmann, 1999; Langford et al., 2005). These investigations reveal unusually high maximum depolarisation ratios $\delta_{\mathrm{p}}$ of $0.5-0.7$. In a few cases, Del Guasta and Niranjan (2001) observed maximum $\delta_{\mathrm{p}}$ values of even larger than 0.8 .
The knowledge of the link between $\delta_{\mathrm{p}}$ of the cirrus ice crystals and their size and shape is a prerequisite for the interpretation of these lidar observations. The scattering matrix of small non-spherical ice crystals with sizes less than about $10 \mu \mathrm{m}$ can be calculated by the T-matrix method. Maximum depolarisation ratios that are comparable to the above lidar observations were found for prolate and oblate spheroidal as well as for oblate cylindrical ice particles with sizes of only a few micrometer (Mishchenko and Sassen, 1998).

In order to investigate the relation between the linear backscattering depolarisation ratio $\delta_{\mathrm{p}}$ and the microphysical properties of small ice particles that might closely resemble those in contrails and cirrus, we have started to perform dedicated ice crystal nucleation and growth experiments at the large cloud simulation chamber Aerosol Interaction and Dynamics in the Atmosphere (AIDA) of the Karlsruhe Institute of Technology. Such studies became feasible after the installation of the new laser scattering and depolarisation setup SIMONE $^{1}$ at the chamber in 2006. SIMONE has been successfully employed in several AIDA campaigns on the homogeneous and heterogeneous nucleation of ice particles (Wagner et al., 2007; Saunders et al., 2010; Steinke et al., 2011), in studies on the depolarisation characteristics of ice clouds generated under defined temperature and humidity conditions (Amsler et al., 2009; Schön et al., 2011; Abdelmonem et al., 2011), as well as for probing phase transitions in inorganic and organic aerosols (Wagner et al., 2010, 2011).

The purpose of the present paper is twofold: we first give a detailed description of the SIMONE instrument including the validation of the measurement set up with water droplet clouds and model aerosol particles. Thereafter, we discuss the depolarisation data measured by SIMONE in simulated ice clouds consisting of small ice particles with sizes in the range from about 1 to $15 \mu \mathrm{m}$. The light scattering data are analysed in the context of the microphysical properties of the clouds measured by single particle light scattering and infrared extinction spectroscopy. We compare our experimental results with theoretical results computed by the T-matrix method for spheroidal particles and finite cylinders in the $\phi=0.25$ to 4.0 aspect ratio range and give conclusions for the interpretation of atmospheric lidar measurements in upper tropospheric ice clouds.

A detailed description of the light scattering instrument SIMONE is given in Sect. 2 together with a brief outline of the cloud simulation chamber AIDA and its instrumentation. The theoretical formalism and the optical model used to compare our experimental results with the T-matrix method is described in Sect. 3. Results of experiments on the growth of supercooled water droplets and the light scattering and depolarisation properties of spheroidal iron oxide particles

\footnotetext{
${ }^{1}$ SIMONE is the acronym for the German project title Streulichtintensitätsmessungen zum optischen Nachweis von Eispartikeln which means Scattering Intensity Measurements for the Optical Detection of Ice Particles.
} 
are presented in Sect. 4 in conjunction with three ice cloud growth experiments. Implications for atmospheric studies are discused in Sect. 5 followed by a conclusion and outlook in Sect. 6.

\section{Experimental methods}

\subsection{The laser scattering and depolarisation instrument SIMONE}

The laser light scattering and depolarisation instrument SIMONE is installed at the first level of the aerosol and cloud simulation chamber AIDA. Optical boards are mounted outside the insulated housing of the chamber on two flanges facing each other (Fig. 1). The optical boards are encapsulated by light-tight housings and are divided in two light-tight sections for the laser beam path and the detection apertures. Separate anti-reflecting windows are used for the laser beam and detection paths in order to minimize back-reflection and cross talk by multi-reflection and scattering on the surfaces of the windows. Moreover, the laser exit window is tilted by $30^{\circ}$ in order to eliminate the residual back-reflected light in a specifically designed light dump which is attached to tube of the window flange (Fig. 2). The transmitted light is eliminated in a second, commercial beam dump. Since the windows are located outside the insulated housing of the chamber, the window flanges can be heated by foil heaters to avoid the condensation of water from ambient air in situations when the chamber is operated at cold temperatures.

SIMONE uses a cw semiconductor laser (Sapphire 488LP, Coherent Inc., USA) with an emission wavelength of $\lambda=$ $488 \mathrm{~nm}$ to generate a polarised and collimated light beam which is directed horizontally along the $4 \mathrm{~m}$ diameter of the cylindrically shaped AIDA chamber. The polarisation vector of the light beam can be arbitrarily changed by using a liquid crystal polarisation rotator (LPR-100- $\lambda$, Meadowlark Optics) in front of the laser head. Usually, it is aligned either parallel or perpendicular to the scattering plane. The latter is defined by the light beam and the overlapping detection apertures of two telescope optics that probe scattered light from the centre of the chamber from the $2^{\circ}$ and $178^{\circ}$ directions. It is important to note here that the mechanical setup constrains these detection angles to an accuracy range of about $\pm 0.5^{\circ}$. The actual detection angles, however, are depending on the final optical alignment of the telescopes and the laser beam and has to be deduced in a specific droplet experiment (see Sect. 4.1). The telescope optics are composed of an objective/ocular lens pair with apertures of $24 \mathrm{~mm}$ and $11.5 \mathrm{~mm}$, respectively. The lens pairs of the forward and backward detection set up have focal length ratios of $230 \mathrm{~mm} / 50 \mathrm{~mm}$ and $200 \mathrm{~mm} / 50 \mathrm{~mm}$, respectively. The distance of the lenses is aligned in a way that their focal points are coinciding at the position of a pinhole (Fig. 3). In order to confine the acceptance angle of the telescope detection apertures to values $\leq 1.5 \mathrm{mrad}$, a pinhole diameter of $0.3 \mathrm{~mm}$ was chosen. The intersection between the laser beam and the detection apertures defines a detection volume of approximately $7 \mathrm{~cm}^{3}$ in the centre of the chamber. The backscattered light is decomposed by a Glan-Laser prism according to the parallel and perpendicular components with respect to the incident laser polarisation. The corresponding intensity components $I_{\perp}$ and $I_{\|}$are measured by two photomultiplier modules R1 and R2 (MP-1383, Perkin Elmer), each equipped with an interference filter to reduce stray light noise. A motor-driven filter wheel equipped with different neutral filters with transmissions down to $1 \%$ is installed in front of the $\mathrm{R} 2$ detector to prevent detector saturation in cases of high particle concentrations in the chamber. From these measurements the nearbackscattering particle linear depolarisation ratio $\delta_{\mathrm{H}, \mathrm{V}}$ is determined by

$\delta_{\mathrm{H}, \mathrm{V}}=\frac{I_{\perp}-I_{\perp}^{\mathrm{bg}}}{I_{\|}-I_{\|}^{\mathrm{bg}}}$,

with $I_{\|}^{\mathrm{bg}}$ and $I_{\perp}^{\mathrm{bg}}$ denoting the background intensities of the particle-free chamber. For the sake of simplicity, we have omitted the subscript p in Eq. (1) and, in accordance with the literature (e.g., Takano and Jayaweera, 1985), the subscript $\mathrm{H}$ or $\mathrm{V}$ indicates that the incident light is polarised parallel or perpendicular to the scattering plane.

The intensity $I_{\mathrm{f}}$ of light scattered in the $2^{\circ}$ direction is detected in exactly the same way apart from the Glan-Laser prism that is useless in case of small scattering angles since light scattering in near-forward direction is not depolarising. The corresponding photomultiplier VR is also equipped with a motorised filter wheel with the same set of neutral filters as in case of the R2 detector, but has an additional fixed neutral filter with $0.5 \%$ transmission, i.e. the minimum applicable transmission is $0.005 \%$. From the three intensity measurements $I_{\mathrm{f}}, I_{\|}$, and $I_{\perp}$ the scattering ratio

$\rho=\frac{I_{\mathrm{f}}}{I_{\|}+I_{\perp}}$

is then calculated.

The fact that the $2^{\circ}$ and $178^{\circ}$ detection apertures are facing each other can be used to align the detection geometry of the instrument. In order to align the two detection directions, the aperture of the forward telescope can be visualised by illuminating its ocular lens from the detector side with the collimated emission of a HeNe Laser. Then the viewing directions of the two telescopes are varied until the HeNe light emitted through the forward telescope passes completely the entrance pupille and the pinhole of the backward telescope, i.e. until the optical axes of the two telescopes are congruent. After the detection apertures have been adjusted, the laser direction is aligned to overlap with the detection apertures in the center of the chamber. In order to visualise this alignment, a scattering target (Spectralon diffuser, Labsphere, USA) can 


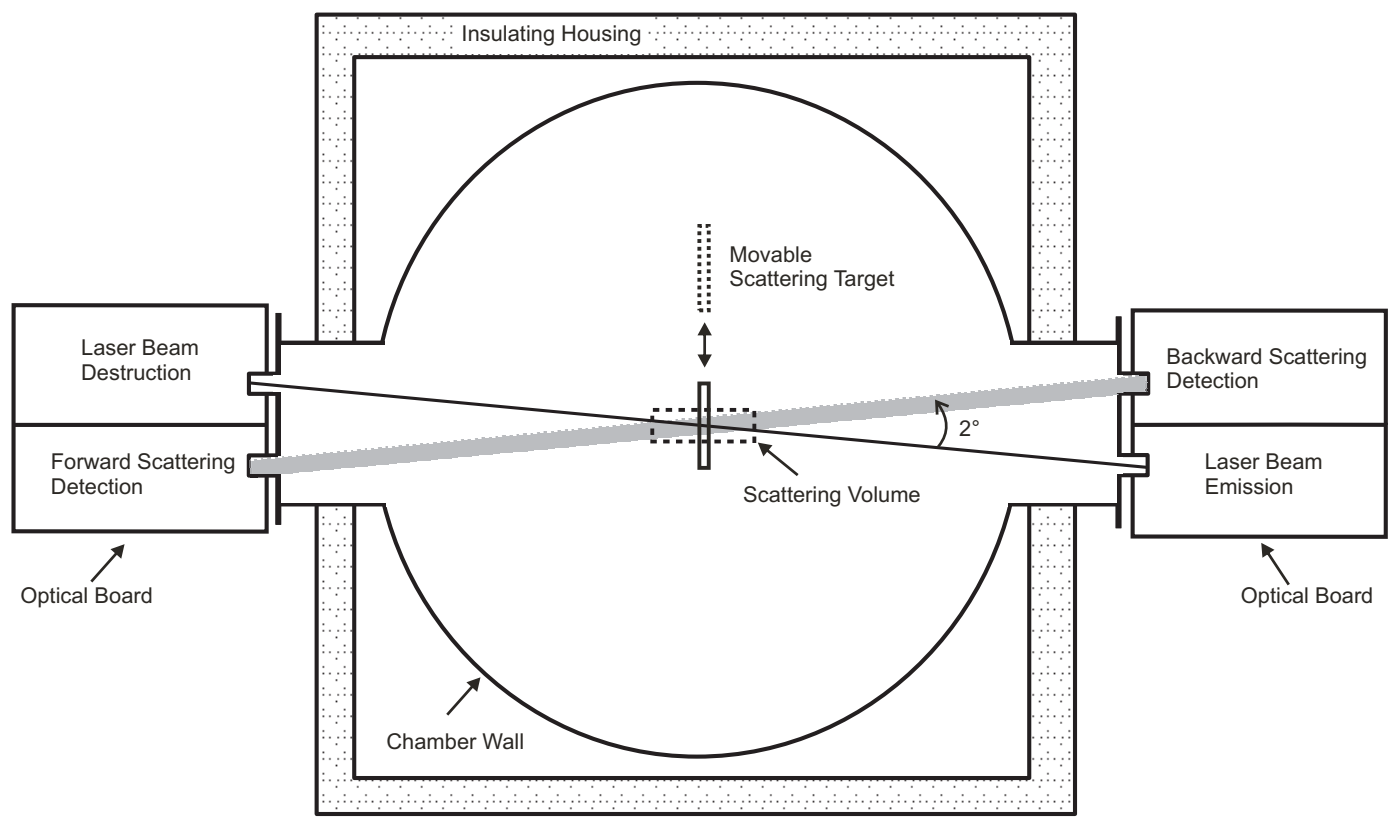

Fig. 1. Horizontal cross section view of the first AIDA level showing the scattering plane of the SIMONE instrument. The SIMONE installation boards are directly mounted on two opposite AIDA flanges that were extended to beyond the insulating housing of the chamber. Note that the scattering target is not moving horizontally as indicated in the scheme, but vertically with respect to the scattering plane.

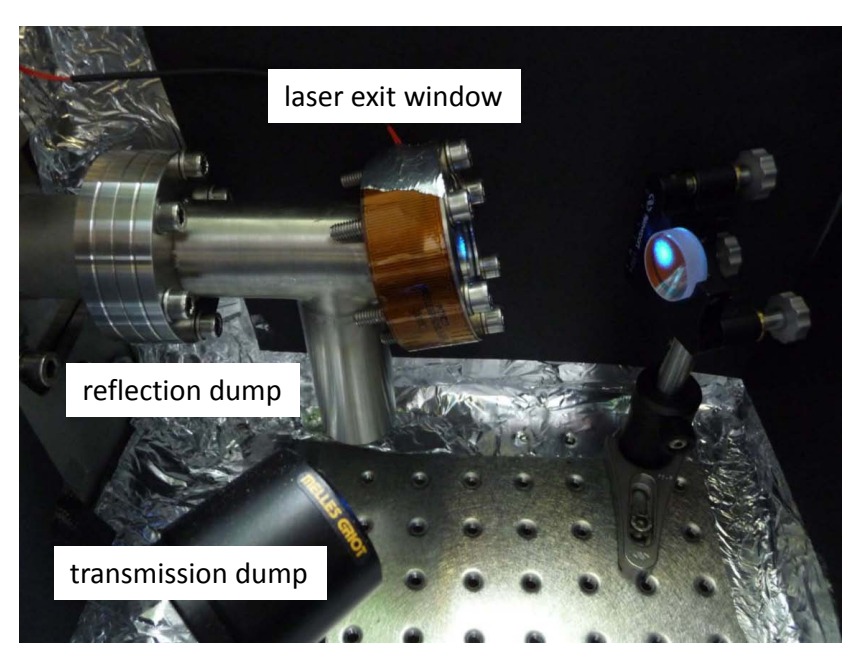

Fig. 2. Home-made laser exit port equipped with anti-reflection window and back-reflection dump. See text for details.

be vertically moved into the scattering centre, so that the optical axes of the telescopes and the laser beam are penetrating the target at near-normal angles. The laser direction is then aligned to get an overlap between the bright spots of the laser beam and the HeNe laser illuminated detection apertures on the scattering target (Fig. 4). Since the Spectralon diffuser is highly depolarising, the scattering target is also used to align the gains of the two backward photomultipliers. The polarisation characteristic of Spectralon was measured by Haner et al. (1999). These measurements clearly show the diffu- sional scattering characteristic of the Spectralon surface with an angular dependent depolarisation ratio larger than about 0.9. At near-normal incidence and at small detection angles a remaining retroreflectance peak confines the depolarisation ratio to about 0.92 . An example of such a photomultiplier adjustment cycle is shown in Fig. 4. It was found that the adjustment factor is changing slightly from experiment to experiment within the range from about 0.91 to 0.97 but with most of the values centered around 0.92 . It is noteworthy that the depolarisation ratio after the adjustment procedure gives exactly the value measured by Haner et al. (1999) for Spectralon at near-normal incidence.

The adjustment cycles are also used to deduce the relative uncertainties $\Delta I=1.3 \%$ and $\Delta \delta=1.4 \%$ of the backscattering signals and depolarisation ratios.

\subsection{The cloud simulation chamber AIDA}

The experiments were conducted at the cloud simulation chamber AIDA (Aerosol Interactions and Dynamics in the Atmosphere) of the Karlsruhe Institute of Technology which can be operated as a moderate cloud expansion chamber to simulate the adiabatic cooling conditions of ascending air parcels in the atmosphere (Benz et al., 2005; Möhler et al., 2005). A detailed description of the chamber preparation, the chamber instrumentation, and the expansion cooling technique for ice cloud studies is given in the recent papers by Wagner et al. $(2010,2011)$. In the following, we therefore only give a brief introduction to the chamber and its intrumentation. 


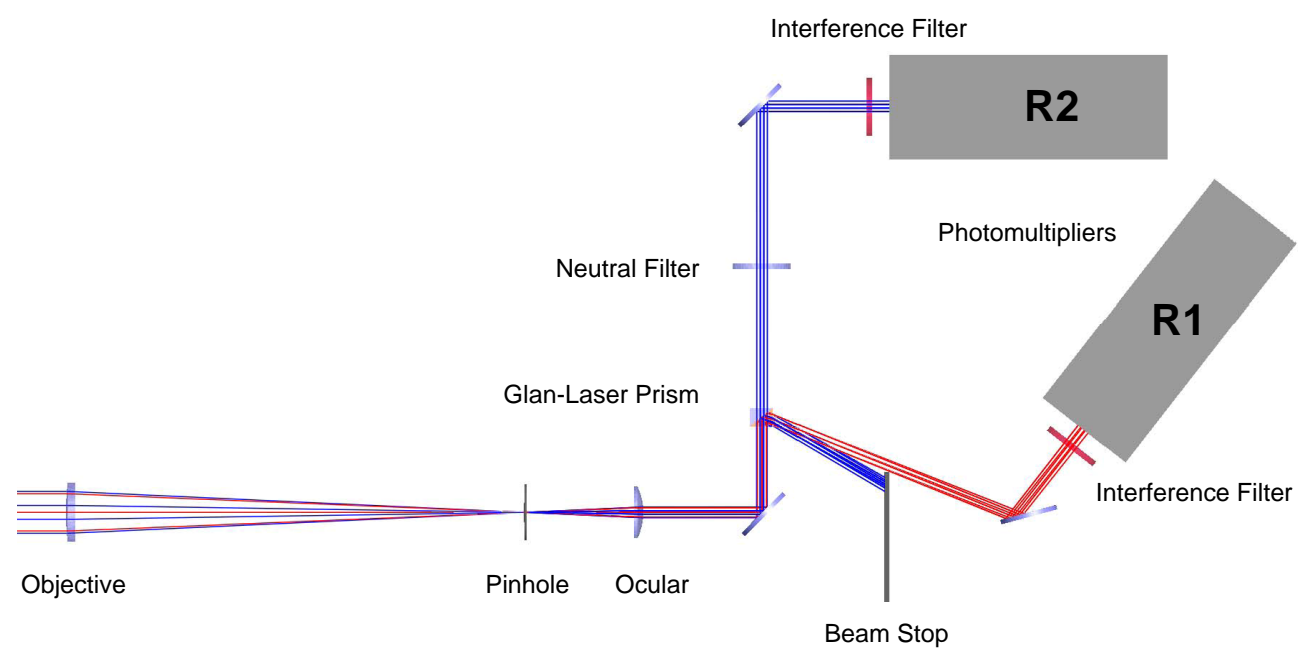

Fig. 3. Backward detection setup composed of telescope optics, Glan-Laser prism, neutral filter (wheel), and two photomultiplier detectors $(\mathrm{R} 1, \mathrm{R} 2)$.
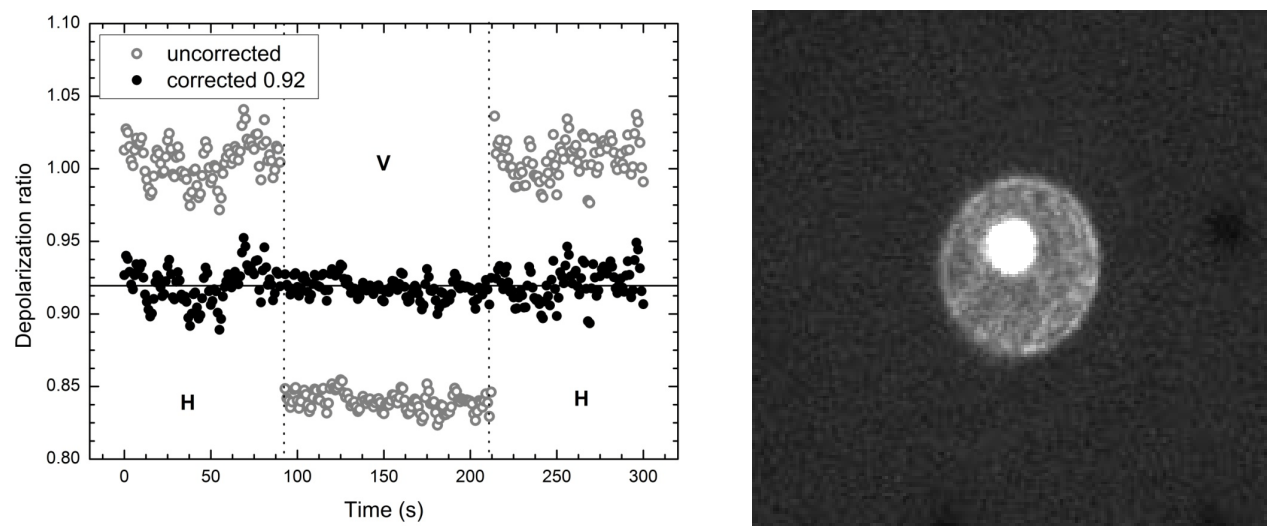

Fig. 4. Left: adjustment cycle for the backscattering photomultiplier signals using a Spectralon scattering target. A tuning factor of 0.92 was utilised in the R1 signal in order to get the same depolarisation ratio of 0.92 for parallel $(\mathrm{H})$ and perpendicular (V) incident polarisation. Note that the R1 photomultiplier detects $I_{\perp}$ in case of parallel and $I_{\|}$in case of perpendicular incident polarisation. Right: overlap between the SIMONE laser beam (small bright spot) and the illuminated detection aperture on the scattering target. Note that this photo was taken by a CCD camera equipped with a zoom objective that is permanently installed at the AIDA chamber for routine checks of the SIMONE alignment.

Figure 5 shows a schematic of the cloud chamber facility consisting of a $84 \mathrm{~m}^{3}$ aluminum vessel that is located inside an insulated housing. The interior of the housing can be cooled to any temperature down to $183 \mathrm{~K}$ by means of two heat exchangers operated either by a refrigerating machine or by liquid nitrogen. Homogeneous temperature, humidity, and particle concentrations inside the vessel are achieved by the continuous operation of a mixing fan, located at the bottom of the chamber. In this way the spatial temperature variability, measured by a set of horizontally and vertically arranged temperature sensors, is reduced to values less than $0.3 \mathrm{~K}$. The expansion cooling cycles are conducted by reducing the chamber pressure by means of a vacuum pump, which has a maximum pumping speed of $240 \mathrm{~m}^{3} \mathrm{~h}^{-1}$. By controlling the pumping speed, different initial adiabatic cooling rates in the range of 0.1 to $4 \mathrm{~K} \mathrm{~min}^{-1}$ can be achieved.

The chamber is equipped with a variety of measurement devices including in situ water vapour measurements by tunable diode laser (TDL) absorption spectroscopy as well as aerosol and cloud particle characterisation by optical particle counters and size analysers (WELAS, SID3), cloud particle imaging (PHIPS), size distribution retrieval by in situ FTIR extinction spectroscopy, and laser scattering and depolarisation measurements (SIMONE). An overview of this optical instrumentation can be found in the recent review by Wagner et al. (2009). The Small Ice Detector Mark 3 (SID3) is a relatively novel aircraft cloud probe that measures highly resolved 2-D forward scattering patterns of individual 


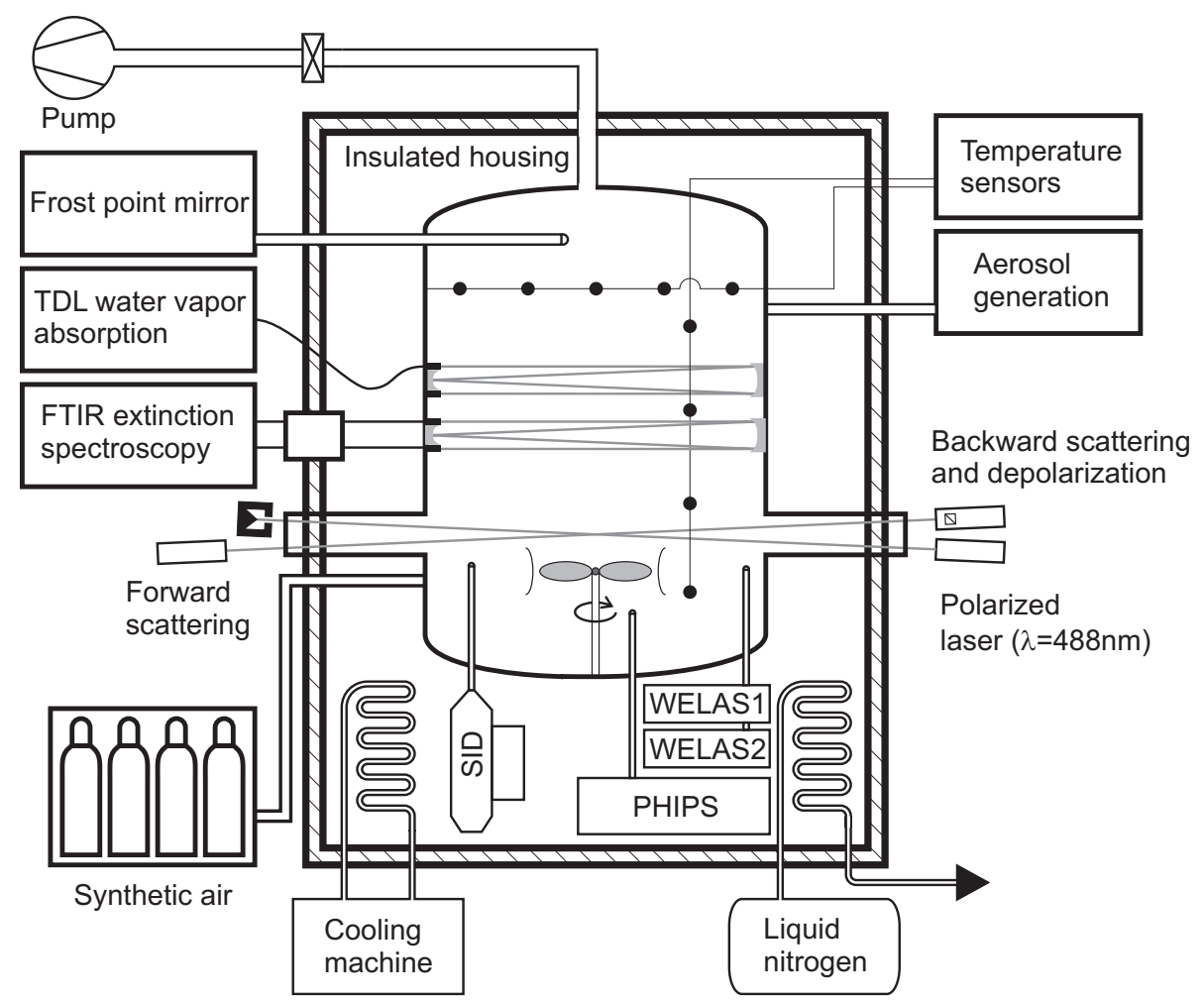

Fig. 5. Scheme of the aerosol and cloud simulation chamber AIDA including the instrumentation used in the present study.

particles. The instrument is currently prepared for the operation onboard the new German research aircraft HALO. SID3 scattering patterns contain detailed information about the particle size, shape, and surface properties (Kaye et al., 2008). In the present work, the SID3 data sets were analysed to derive the cloud particle size distributions. In case of the ice cloud experiments discussed in Sect. 4.3, the SID3 particle size analysis is based on the scattering intensity while for the supercooled droplet experiment (Sect. 4.1) a Mie analysis of the Airy diffraction patterns was conducted.

The cloud expansion experiments of this study were conducted at initial temperatures between $254 \mathrm{~K}$ and $188 \mathrm{~K}$ starting from ambient pressure. The chamber was humidified to near ice saturated conditions prior to the experiments. Interstitial water vapour concentration within the chamber is determined by the TDL spectrometer. A chilled mirror frost point hygrometer equipped with a heated stainless steel sampling tube is used to determine the total (cloud particle and vapour) water concentration.

\section{Modeling of the light scattering properties by means of the T-matrix method}

\subsection{The Mueller-Stokes calculus}

For the theoretical analysis of the measurements at the AIDA chamber, we need to express the depolarisation defined in Eq. (1) by the elements $S_{\mathrm{ij}}$ of the $4 \times 4$ Mueller scattering matrix $\mathbf{S}$. By means of the definition of the Stokes vector $(I, Q, U, V)$ (van de Hulst, 1981), the intensities in Eq. (1) can be written as follows:

$I_{\perp}-I_{\perp}^{\mathrm{bg}}=\frac{I_{\text {sca }}-Q_{\text {sca }}}{2}$
$I_{\|}-I_{\|}^{\mathrm{bg}}=\frac{I_{\text {sca }}+Q_{\text {sca }}}{2}$

for a incident laser polarisation that is parallel to the scattering plane, and

$I_{\perp}-I_{\perp}^{\mathrm{bg}}=\frac{I_{\mathrm{sca}}+Q_{\mathrm{sca}}}{2}$
$I_{\|}-I_{\|}^{\mathrm{bg}}=\frac{I_{\mathrm{sca}}-Q_{\mathrm{sca}}}{2}$

for perpendicular polarised incident light. In Eqs. (3)-(6) $I_{\text {sca }}$, and $Q_{\text {sca }}$ are the elements of the Stokes vector of the scattered light. Please note that $I_{\perp}$ and $I_{\|}$are defined with respect to the polarisation of the incident light, but not with 
respect to the scattering plane (cf. Sect. 2.1). The Stokes vector of the incident light has the components $I_{\text {inc }}, Q_{\text {inc }}=I_{\text {inc }}$, $U_{\text {inc }}=V_{\text {inc }}=0$ for parallel and $I_{\text {inc }}, Q_{\text {inc }}=-I_{\text {inc }}, U_{\text {inc }}=$ $V_{\text {inc }}=0$ for perpendicular polarisation. $I_{\text {sca }}$ and $Q_{\text {sca }}$ are obtained by applying the Mueller matrix to the incident Stokes vector

$I_{\mathrm{sca}}=\frac{S_{11}+S_{12}}{k^{2} R^{2}} I_{\mathrm{inc}}$

$Q_{\text {sca }}=\frac{S_{12}+S_{22}}{k^{2} R^{2}} I_{\text {inc }}$

for parallel polarisation and

$$
\begin{aligned}
& I_{\mathrm{sca}}=\frac{S_{11}-S_{12}}{k^{2} R^{2}} I_{\mathrm{inc}} \\
& Q_{\text {sca }}=\frac{S_{12}-S_{22}}{k^{2} R^{2}} I_{\mathrm{inc}}
\end{aligned}
$$

for perpendicular incident laser polarisation. The constant $R$ is the distance from the scatterer and $k$ is the wavenumber. For deriving Eqs. (8) and (10), use has been made of the relation $S_{21}=S_{12}$. This is valid for random particle orientation (Mishchenko, 2009). Inserting Eqs. (3)-(10) into Eq. (1) gives

$\delta_{\mathrm{H}}=\frac{S_{11}-S_{22}}{S_{11}+2 S_{12}+S_{22}}$

and

$\delta_{\mathrm{V}}=\frac{S_{11}-S_{22}}{S_{11}-2 S_{12}+S_{22}}$.

Equations (11) and (12) are identical to the equations for the linear depolarisation ratios $\delta_{\mathrm{H}}$ and $\delta_{\mathrm{V}}$ in Takano and Jayaweera (1985).

In contrast to the SIMONE scattering geometry, atmospheric lidar applications detect backscattered light at $180^{\circ}$. According to Mishchenko (2009) the element $S_{12}$ in Eqs. (11) and (12) is zero for the scattering angles $\theta=0^{\circ}$ and $\theta=180^{\circ}$ and, thus, the depolarisation ratio at $\theta=180^{\circ}$ is independent of the incident laser polarisation and depends only on the ratio $S_{22} / S_{11}$

$\delta_{\text {lidar }}=\frac{S_{11}-S_{22}}{S_{11}+S_{22}}$.

The ratio $S_{22} / S_{11}$ can also be deduced from SIMONE measurements provided that depolarisation measurements have been performed for both incident laser polarisations (Eqs. 11 and 12)

$\frac{S_{22}}{S_{11}}=\frac{1+\delta_{\mathrm{H}} / \delta_{\mathrm{V}}-\delta_{\mathrm{H}}}{1+\delta_{\mathrm{H}} / \delta_{\mathrm{V}}+\delta_{\mathrm{H}}}$.

It is important to note here that the ratio given in Eq. 14 is only valid for the SIMONE detection angle, i.e. $178^{\circ}$, and can be different from the ratio at $180^{\circ}$.
The question whether the SIMONE depolarisation measurements are useful for the interpretation of atmospheric lidar data will be addressed in Sect. 5 when discussing the Tmatrix modelling results for spheroidal particles and finite cylinders. The methodology of these computations is outlined in the following section.

\subsection{T-matrix calculations}

We have performed T-matrix calculations for spheroidal and cylindrical particles using the publicly available FORTRAN T-matrix code by Mishchenko and Travis (1998). We used this method because it was applied in the study by Mishchenko and Sassen (1998) for the interpretation of lidar measurements of small ice particles in contrails and contrail cirrus. We are aware of the fact that spheroidal and cylindrical particle shapes are only rough approximations of the hexagonal morphology of natural ice particles. However, the aim of this modelling study was to deduce the general dependency of the SIMONE depolarisation ratio on the particle size and aspect ratio and to provide a basis for the interpretation of our AIDA ice cloud experiments at cirrus temperatures.

For this purpose, we have first calculated the Mueller matrices of randomly oriented spheroidal and cylindrical particles for different size parameters $x=\pi D_{\mathrm{v}} / \lambda$ (with $D_{\mathrm{v}}$ the equal-volume sphere diameter and $\lambda=488 \mathrm{~nm}$ the laser wavelength), aspect ratios $\phi$, and for a fixed complex refractive index of $m=1.31+i 10^{-9}$. We have calculated the Mueller matrices for 29 lognormally spaced $\phi$ values in the $\phi=0.25-4$ range and for $88 x$ values on a combined linear/logarithmic grid in the $x=0.02-50$ range. Note that for size parameters larger than about 20 , due to convergence reasons, the calculations are restricted to the $\phi=0.45-2.22$ and $\phi=0.5-2.0$ ranges for spheroidal and cylindrical particles, respectively.

These Mueller matrix look-up tables were then used to model the SIMONE measurement results of our AIDA ice cloud experiments presented in Sect. 4.3. In these modelling runs, the size distribution retrieval of the FTIR extinction measurements was used to calculate the Mueller matrix elements $\left\langle S_{11}\right\rangle,\left\langle S_{12}\right\rangle$ and $\left\langle S_{22}\right\rangle$ of the ice particle ensemble by solving the integral

$\left\langle S_{\mathrm{ij}}\right\rangle=\frac{1}{\left\langle C_{\mathrm{sca}}\right\rangle} \int_{D_{\mathrm{v}}^{\min }}^{D_{\mathrm{v}}^{\max }} \mathrm{d} D_{\mathrm{v}} n\left(D_{\mathrm{v}}\right) C_{\mathrm{sca}}\left(D_{\mathrm{v}}\right) S_{\mathrm{ij}}\left(D_{\mathrm{v}}\right)$

numerically (Mishchenko, 1993). In Eq. (15) $\left\langle C_{\text {sca }}\right\rangle$ is the ensemble-averaged scattering cross section:

$\left\langle C_{\mathrm{sca}}\right\rangle=\int_{D_{\mathrm{v}}^{\min }}^{D_{\mathrm{v}}^{\max }} \mathrm{d} D_{\mathrm{v}} n\left(D_{\mathrm{v}}\right) C_{\mathrm{sca}}\left(D_{\mathrm{v}}\right)$ 
and $n\left(D_{\mathrm{v}}\right)$ the lognormal size distribution given by the FTIR retrieval

$n\left(D_{\mathrm{v}}\right)=\frac{N}{\sqrt{2 \pi} \ln 10 D_{\mathrm{v}} \log \sigma_{\mathrm{g}}} \exp \left[-\frac{\log ^{2}\left(D_{\mathrm{v}} / \overline{D_{\mathrm{v}}}\right)}{2 \log ^{2} \sigma_{\mathrm{g}}}\right]$

with $N$ the particle number concentration, $\overline{D_{\mathrm{v}}}$ the count median equal-volume sphere diameter, and $\sigma_{\mathrm{g}}$ the mode width. $n\left(D_{\mathrm{v}}\right) \mathrm{d} D_{\mathrm{v}}$ represents the fraction of particles per unit volume having diameters between $D_{\mathrm{v}}$ and $D_{\mathrm{v}}+\mathrm{d} D_{\mathrm{v}}$. Finally, the ensemble-averaged Mueller matrix elements of Eq. (15) were used in Eqs. (7) and (9) to calculate the SIMONE scattering signals:

$I_{\text {sca }}\left(2^{\circ}\right)=b\left(\left\langle S_{11}\right\rangle_{2^{\circ}} \pm\left\langle S_{12}\right\rangle_{2^{\circ}}\right)\left\langle C_{\text {sca }}\right\rangle N$

for the forward direction and

$I_{\text {sca }}\left(178^{\circ}\right)=b\left(\left\langle S_{11}\right\rangle_{178^{\circ}} \pm\left\langle S_{12}\right\rangle_{178^{\circ}}\right)\left\langle C_{\text {sca }}\right\rangle N$

for the backward direction with the prefactor $b$ defined by the scattering distance, the detection aperture, and the laser intensity. The prefactor $b$ was deduced in a droplet experiment that will be discussed in Sect. 4.1. Inserting Eq. (15) in Eqs. (11) and (12) gives the modelling results for the linear depolarisation ratios, accordingly.

The FTIR retrieval strategy that has been developed by Wagner et al. (2006) is also based on the FORTRAN Tmatrix code for randomly oriented particles by Mishchenko and Travis (1998). Initially, look-up tables of extinction cross section spectra were calculated for finite cylinders with diameter to length ratios of $\phi=0.5,0.7,1.0,2.0$, and 3.0. The spectra were calculated on a grid of discrete equal-volume sphere diameters from 0.1 to $25.0 \mu \mathrm{m}$ at equidistant size steps of $0.15 \mu \mathrm{m}$. A lognormal size distribution was assumed in the least square fitting procedure retrieving the count median equal-volume sphere diameter $\left(\overline{D_{\mathrm{v}}}\right)$ and the mode width $\sigma_{\mathrm{g}}$. For the small ice particle ensembles discussed in Sect. 4.3, the FTIR retrieval results are only slightly dependent on the assumed aspect ratio and the measured FTIR extinction spectra can be well reproduced by assuming a single compact cylindrical particle shape with $\phi=0.7$. Thus, there is no evidence for strongly aspherical ice particles in our experiments in contrast to Wagner et al. (2006) who sometimes had to assume ice particle shape distributions to match the FTIR extinction spectra, especially for larger ice particles with $D_{\mathrm{v}}>6 \mu \mathrm{m}$.

\section{Results}

In the following sections, the capabilities of SIMONE in terms of measuring the absolute linear depolarisation ratio are presented for supercooled cloud droplets, spheroidal hematite particles, and ice clouds consisting of small ice particles with sizes in the range from about 1 to $15 \mu \mathrm{m}$.

\subsection{Supercooled water droplets}

Supercooled water droplet experiments are ideally suited to deduce the adjustment factor that corrects the gain differences between the forward and backward photomultipliers VR and R2, to deduce the prefactor $b$ of Eqs. (18) and (19), and to determine the exact detection angles of the SIMONE telescopes. It has been shown in previous chamber expansion experiments that graphitic soot is an appropriate seed aerosol type for the generation of supercooled water clouds in the AIDA chamber. These soot particles are activated to water droplets with a narrow size distribution when achieving water saturated conditions during the expansion cooling. Furthermore, graphitic soot particles do not nucleate ice at temperatures above $-30^{\circ} \mathrm{C}$, neither by deposition nucleation nor by immersion freezing.

The HALO06_2 experiment was conducted with soot particles generated with a commercial graphite spark generator (GFG 1000, Palas, Germany) as seed aerosol particles. The generator was operated at its maximum spark frequency setting and with purified Argon as carrier gas, which was set at a flow rate of $51 \mathrm{~min}^{-1}$. After passing a coagulation tube of $0.5 \mathrm{~m}$ length and $40 \mathrm{~mm}$ i.d., the soot aerosol was directly added to the AIDA chamber, which was preconditioned to a temperature of $254 \mathrm{~K}$ and a relative humidity with respect to water of $78 \%$. Due to the high particle production rate of the spark generator, the AIDA chamber was filled within $2 \mathrm{~s}$ with soot aerosol particles to a final number concentration of about $40 \mathrm{~cm}^{-3}$. The soot aerosol size distribution, which was characterised with a commercial scanning mobility particle sizer (SMPS, TSI), exhibited a count median mobility diameter of about $150 \mathrm{~nm}$.

Figure $6 \mathrm{a}$ and $\mathrm{b}$ shows the temporal evolution of the pressure, the mean wall and gas temperatures, and the total and interstitial relative humidities with respect to liquid water during the expansion cooling experiment. FTIR extinction spectra were continuously acquired at an acquisition rate of $6 \mathrm{~min}^{-1}$ throughout the experiment. These spectra were used in a Mie fitting procedure to retrieve a lognormal representation of the cloud droplet size distribution. The reader is referred to Wagner et al. (2005) for details of the FTIR retrieval procedure. The time evolution of the FTIR retrieved droplet diameter is depicted in Fig. $6 c$ togther with the size distribution deduced from the single particle measurements by SID3. After the soot particles had been activated at about $100 \mathrm{~s}$ experiment time, when reaching $100 \% \mathrm{RH}$ with respect to supercooled water, the droplets continuously grew to diameters of about $30 \mu \mathrm{m}$ within the expansion cooling period which lasted until $570 \mathrm{~s}$ experiment time. During this period the FTIR retrieved median diameter and width of the droplet size distribution are in excellent agreement with the SID3 single particle diameter distribution, denoting the accuracy of both methods to infer the size of spherical particles based on Mie scattering computations. Both methods reveal a very narrow droplet diameter distribution throughout the growth period, 

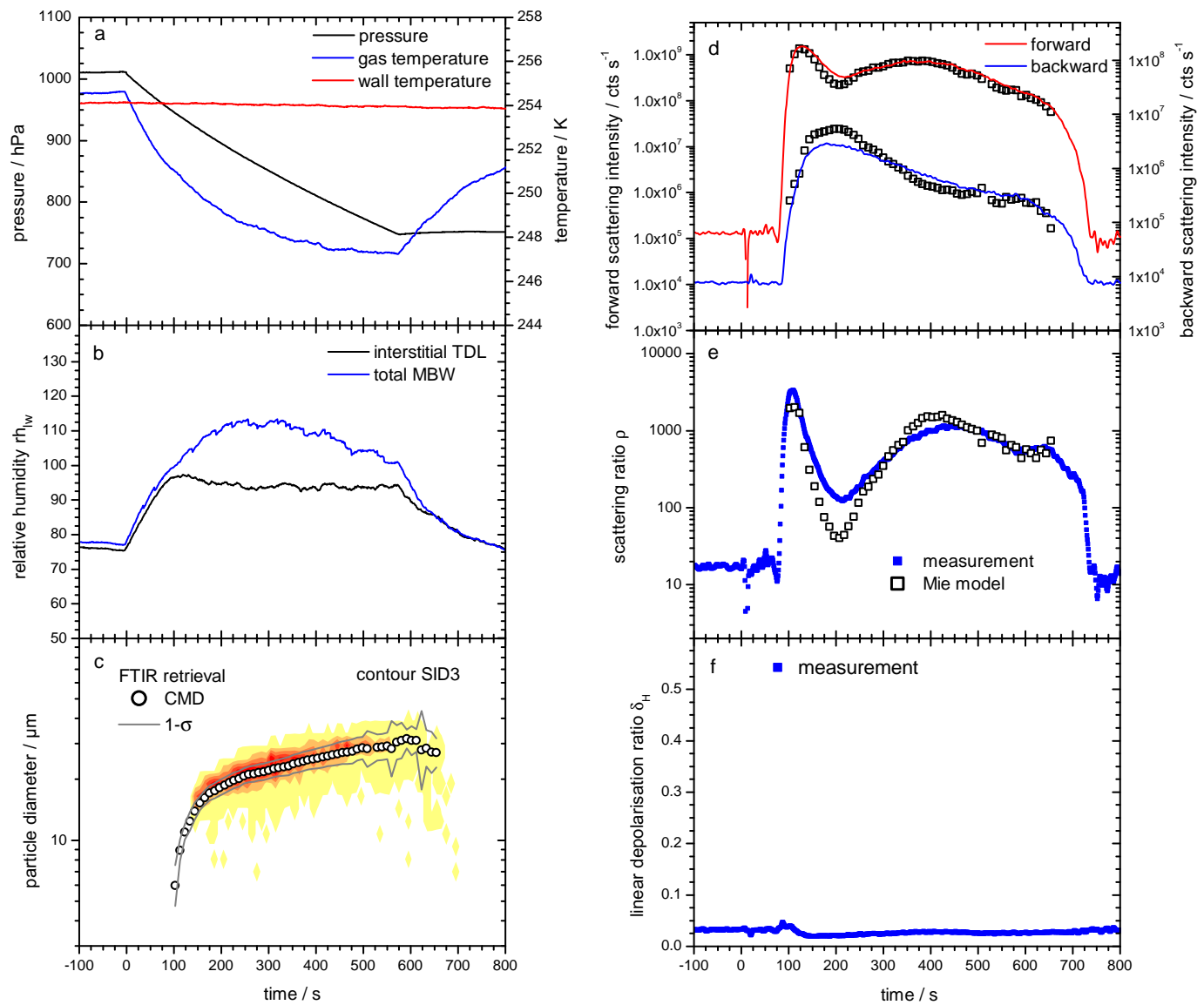

Fig. 6. Supercooled liquid cloud activation experiment HALO06_2. (a) Time evolution of the pressure and the mean gas and wall temperatures. (b) Relative humidities with respect to liquid water of the interstitial water vapour and the total (interstitial + condensed) water mass. (c) Comparison of the droplet size distributions retrieved from the FTIR extinction spectroscopy and deduced from SID3 single particle scattering patterns. (d-f) Comparison of the SIMONE measurement results with the results of the Mie analysis of the FTIR retrieved size distribution shown in (c). Note that the modelled depolarisation value is zero throughout the cloud period and is, therefore, not depicted in (f).

which is also reflected by the Mie interference maxima and minima observed in the SIMONE scattering intensities and the scattering ratio plotted in Fig. 6d, e. During the cloud period, the linear depolarisation ratio stayed at its background value between 0.02 and 0.03 (Fig. 6f). This residual depolarisation even in the presence of only spherical cloud droplets is due to a combination of the finite polarisation ratio of the laser (approximately 100:1), minor misalignments of the optical components, and a small cross talk between the parallel and perpendicularly polarised intensity components in the Glan-Laser prism.

In order to quantify a possible gain difference between the forward and backward scattering detectors and to deduce the prefactor $b$ of Eqs. (18) and (19), the time evolution of the droplet distribution from Fig. 6c was used in a forward Mie calculation to simulate the expected SIMONE scattering intensities of the supercooled droplet cloud. The complex refractive index of $m=1.34+i 10^{-9}$ measured by Segelstein (1981) for liquid water at $25^{\circ} \mathrm{C}$ and $\lambda=490 \mathrm{~nm}$ was used as anchor point for calculating the temperature dependent refractive index of the supercooled water droplets. This was achieved by applying the Lorentz-Lorenz relation together with a parameterisation of the temperature dependence of the water density given by Hare and Sorensen (1987). As already mentioned in Sect. 2.1 the exact detection angles of SIMONE are not known and have to be deduced in a droplet experiment. Therefore, the scattering angles were varied in $0.1^{\circ}$ steps around $2^{\circ}$ and $178^{\circ}$ in our simulations to determine the actual detection angles by the best fit simulation. The results of this simulation are compared in Fig. 6d and e with the measured SIMONE data. Here it turned out that (i) the exact scattering angles are $1.8^{\circ}$ and $178.2^{\circ}$ rather than $2.0^{\circ}$ and $178.0^{\circ}$, (ii) the forward and backward photomultiplier gains agree within $10 \%$, and (iii) the prefactor $b$ is around 264 . The precise determination of the scattering angles was possible because of the narrow droplet distribution which induced a distinct angular Mie interference pattern. 

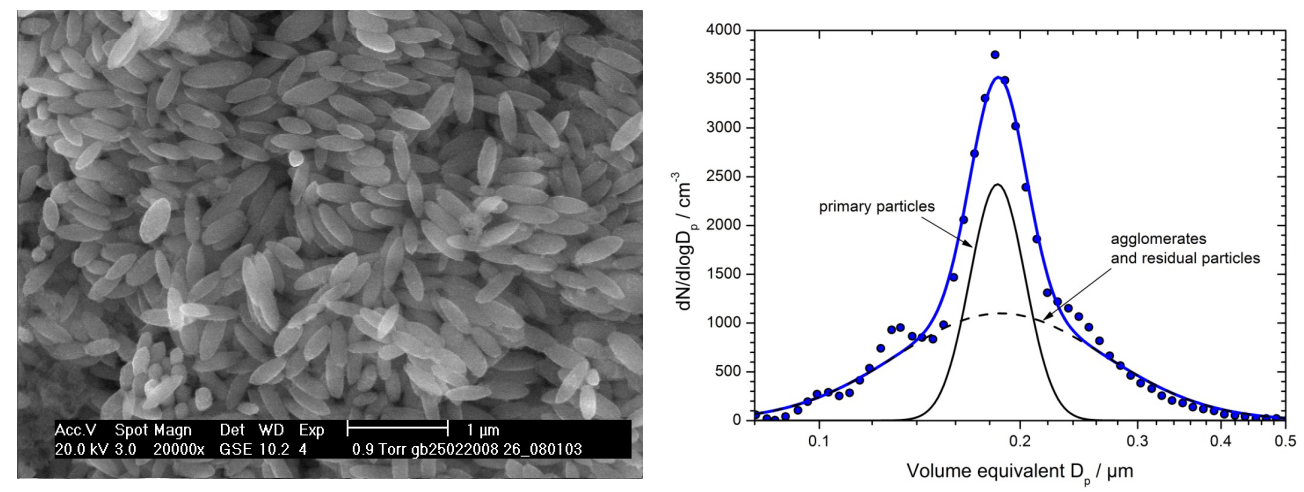

Fig. 7. Left: electron micrograph of the synthetic hematite particle sample used in this study. The aspect ratio of the prolate spheroidal particles was found to be very uniform with a mean value of 0.37 . Right: size distribution of the aerosol sample after dispersion into the AIDA chamber. The narrow mode can be attributed to the primary hematite spheroids while the broad mode is likely induced by residual akaganeit particles and particle agglomerates.

\subsection{Spheroidal iron oxide particles}

Experiments with spheroidal iron oxide (hematite) particles were aimed at the validation of the adjustment factor for the gains of the the two backward photomultipliers R1 and R2. As already mentioned in Sect. 2.1, an adjustment factor of 0.92 was determined exploiding the strong depolarising scattering behaviour of the Spectralon target.

Prolate spheroidal hematite particles with a defined aspect ratio and a narrow size distribution were synthesized in the laboratory according to the procedure described in Ozaki et al. (1984); Morales et al. (1992); Ocana et al. (1995). The procedure is based on the forced hydrolysis of ferric chloride solutions at a temperature of $100^{\circ} \mathrm{C}$ in the precence of sodium dihydrogen phosphate. The first precipitation phase is akaganeit which slowly transforms to hematite particles on an aging time of up to 6 days (Morales et al., 1992). The aerosol sample that has been used in the chamber experiment described here was investigated by scanning electron microscopy to deduce the aspect ratio of the particles (Fig. 7). The aspect ratio of the particles was found to be very uniform with a variation between 0.35 and 0.39 and with a mean value of 0.37 .

A dry powder disperser (TSI, Model 3433) was used to disperse and add the hematite particles to the AIDA chamber that had been conditioned to $249 \mathrm{~K}$ and near-ice saturated conditions. The size distribution of the hematite aerosol in the chamber was measured with a scanning mobility particle sizer (SMPS, TSI). According to Zelenyuk and Imre (2007), a shape factor of 1.3 was applied for the hematite particles to convert the measured mobility equivalent diameters to volume equivalent diameters. The size distribution depicted in Fig. 7 shows a narrow mode of the primary spheroidal particles superimposed on a much broader background mode that is likely due to residual akaganeit particles and particle agglomerates. The measured size distribution was fit- ted by a bimodal log-normal function resulting in the lognormal parameters number density $N$, median diameter $D_{\mathrm{p}}^{\mathrm{m}}$ and standard deviation $\sigma_{\mathrm{g}}$ of $N=579 \mathrm{~cm}^{-3}, D_{\mathrm{p}}^{\mathrm{m}}=185 \mathrm{~nm}$, $\sigma_{\mathrm{g}}=1.1$ and $N=989 \mathrm{~cm}^{-3}, D_{\mathrm{p}}^{\mathrm{m}}=187 \mathrm{~nm}, \sigma_{\mathrm{g}}=1.4$ for the "primaries" and "agglomerates" modes, respectively. The two modes of the model size distribution were used as input to Mishchenko's T-matrix code mentioned in Sect. 3.2 to calculate the depolarisation ratio of the hematite aerosol for a fixed aspect ratio of 0.37 . A complex refractive index of $3.15+i 0.712$ was used in the calculations which corresponds to the $2 / 3$ to $1 / 3$ mixture of the ordinary and extraordinary refractive indices as tabulated in Querry (1987) for $\lambda=490 \mathrm{~nm}$. The applicability of this refractive index for the synthetic hematite aerosol was proved by analysing UVVIS-NIR extinction and absorption spectra that have been measured for the spheroidal particles in a separate work. Examples are given in Wagner et al. (2009) and the complete results of this laboratory work will be the subject of an upcoming paper.

For both linear depolarisation ratios $\delta_{\mathrm{H}}$ and $\delta_{\mathrm{V}}$, almost the same value of 0.22 was calculated. This indicates that the matrix element $S_{12}$ in Eqs. (11) and (12) is very low. Figure 8 shows the temporal evolution of the measured depolarisation ratio together with the temperature and humidity conditions in the chamber. After the addition of the hematite particles to the chamber the light scattering and depolarisation ratio of the aerosol was measured over a period of more than one hour. During this time, SIMONE measured a constant depolarisation ratio of $0.225 \pm 0.006$ for both parallel and perpendicular incident laser polarisation, which is in very good agreement with the modelling result. At time zero, the aerosol was probed in an expansion cooling cycle on its ability to act as cloud condensation or ice nuclei. The aerosol activation and the formation of supercooled droplets is nicely reflected by the sudden drop of the linear depolarisation ratio when the liquid saturation line is surpassed (Fig. 8, 


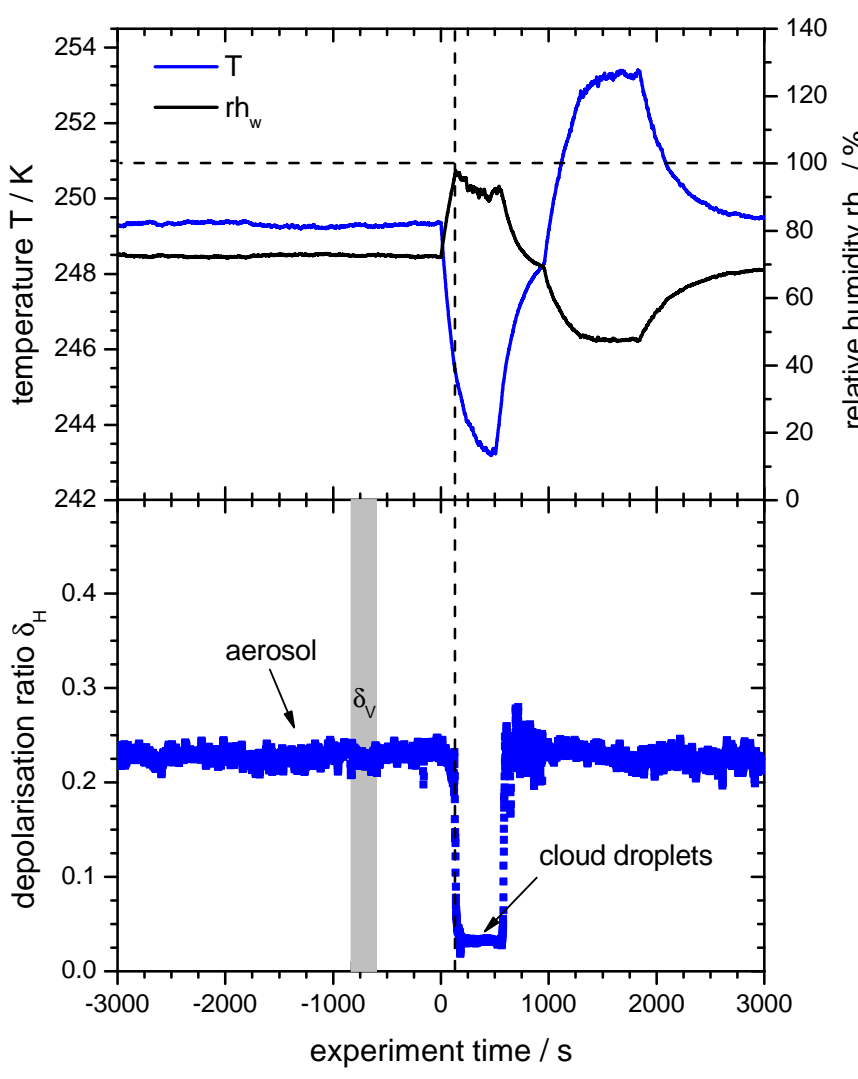

Fig. 8. SIMONE depolarisation evaluation experiment with synthetic hematite aerosol particles. At $t=0 \mathrm{~s}$, the spheroidal particles were activated to form spherical cloud droplets. A constant linear depolarisation ratio of $0.225 \pm 0.006$ was found for $\delta_{\mathrm{H}}$ and $\delta_{\mathrm{V}}$ outside the cloud period which is in very good agreement with the modelled value of 0.22 .

vertical line). At about $500 \mathrm{~s}$ experiment time the expansion was stopped which resulted in a decrease of the relative humidity, the evaporation of the cloud droplets, the release of the hematite particles and, consequently, the recover of the depolarisation ratio.

\subsection{Small ice crystals}

In this section, we describe three ice cloud experiments conducted during the AIDA campaigns ICE01 and HALO06 at initial temperatures of 202, 204, and 224 K. Further examples can be found in Wagner et al. (2009) and Mishchenko (2009). The basic experimental parameters are given in Table 1 . We selected two experiments that were conducted at roughly the same low initial temperature of $\sim 204 \mathrm{~K}$ but with sulphuric acid solution droplets and GSG soot particles as ice nuclei. These experiments contrast the depolarisation properties of ice particles that have been formed via the homogeneous and heterogeneous ice nucleation process. The third experiment with GSG soot particles at a higher initial temperature of $224 \mathrm{~K}$ was selected because the impact of ice par-
Table 1. Overview of the AIDA ice cloud nucleation experiments with small ice particles. $T_{\text {gas }}$ and $N_{\text {ae }}$ represent initial conditions of the mean gas temperature and the aerosol number concentration, respectively. $\overline{D_{\mathrm{v}}}$ gives the median particle diameter at maximum depolarisation ratio $\delta_{\mathrm{H}}^{\max }$ detected by SIMONE. Note that in case of HALO06_30 the maximum depolarisation ratio was detected during ice particle sublimation.

\begin{tabular}{|c|c|c|c|c|c|}
\hline experiment & $\begin{array}{l}\text { nucleation } \\
\text { mode }\end{array}$ & $\begin{array}{r}T_{\text {gas }} \\
(\mathrm{K})\end{array}$ & $\begin{array}{r}N_{\mathrm{ae}} \\
\left(\mathrm{cm}^{-3}\right)\end{array}$ & $\begin{array}{r}\overline{D_{\mathrm{v}}} \\
(\mu \mathrm{m})\end{array}$ & $\delta_{\mathrm{H}}^{\max }$ \\
\hline ICE01_14 & homogeneous & 201.6 & 2790 & 2.1 & 0.31 \\
\hline HALO06_25 & heterogeneous & 224.3 & 320 & $\leq 2.6$ & 0.35 \\
\hline HALO06_30 & heterogeneous & 203.6 & 490 & 2.1 & 0.4 \\
\hline
\end{tabular}

ticle growth and sublimation on the depolarisation ratio was systematically investigated in this experiment.

Due to the low water vapour content available at temperatures below $224 \mathrm{~K}$, the generated ice particles generally remain small in these experiments, with sizes below $10 \mu \mathrm{m}$ for typical ice clouds with particle number concentrations of about $10-100 \mathrm{~cm}^{-3}$ (Cotton et al., 2007; Wagner et al., 2007). Therefore, these low temperature experiments also represent an extension of the ice particle depolarisation studies conducted at warmer temperatures in the context of the characterisation of new ice particle imaging instruments (Amsler et al., 2009; Schön et al., 2011; Abdelmonem et al., 2011).

\subsubsection{Homogeneous nucleation at $T_{\text {initial }}=202 \mathrm{~K}$ (ICE01_14)}

The ICE01_14 experiment was conducted with submicronsized sulphuric acid solution droplets at an initial number concentration of about $2800 \mathrm{~cm}^{-3}$ and with a count median diameter around $120 \mathrm{~nm}$. The reader is referred to Wagner et al. (2008) for details of the aerosol generation.

The temporal evolution of the pressure, the mean wall and gas temperatures, and the ice saturation ratios for interstitial and total water vapour during the AIDA experiment is shown in Fig. 9a, b. Starting from near ice saturated conditions at $t=0 \mathrm{~s}$, the chamber gas was adiabatically cooled from 201.6 to $194.5 \mathrm{~K}$ within $630 \mathrm{~s}$ which at first resulted in a continuous increase of the saturation ratio until the threshold for the homogeneous nucleation of ice in the $\mathrm{H}_{2} \mathrm{SO}_{4}$ solution droplets was reached at about $t=300 \mathrm{~s}$. A threshold saturation ratio for the onset of ice nucleation around 1.68 was determined which is in good agreement with the results of the homogeneous ice nucleation study by Möhler et al. (2003). After the onset of ice nucleation, the saturation ratio further increased to a peak value of 1.75 at $t=330 \mathrm{~s}$ before the growing ice particles started to deplete the water vapour. This short nucleation period resulted in the formation of about 60 ice particles per $\mathrm{cm}^{3}$ chamber volume corresponding to an activated aerosol fraction of $\sim 2 \%$. Figure $9 \mathrm{c}$ depicts the temporal 

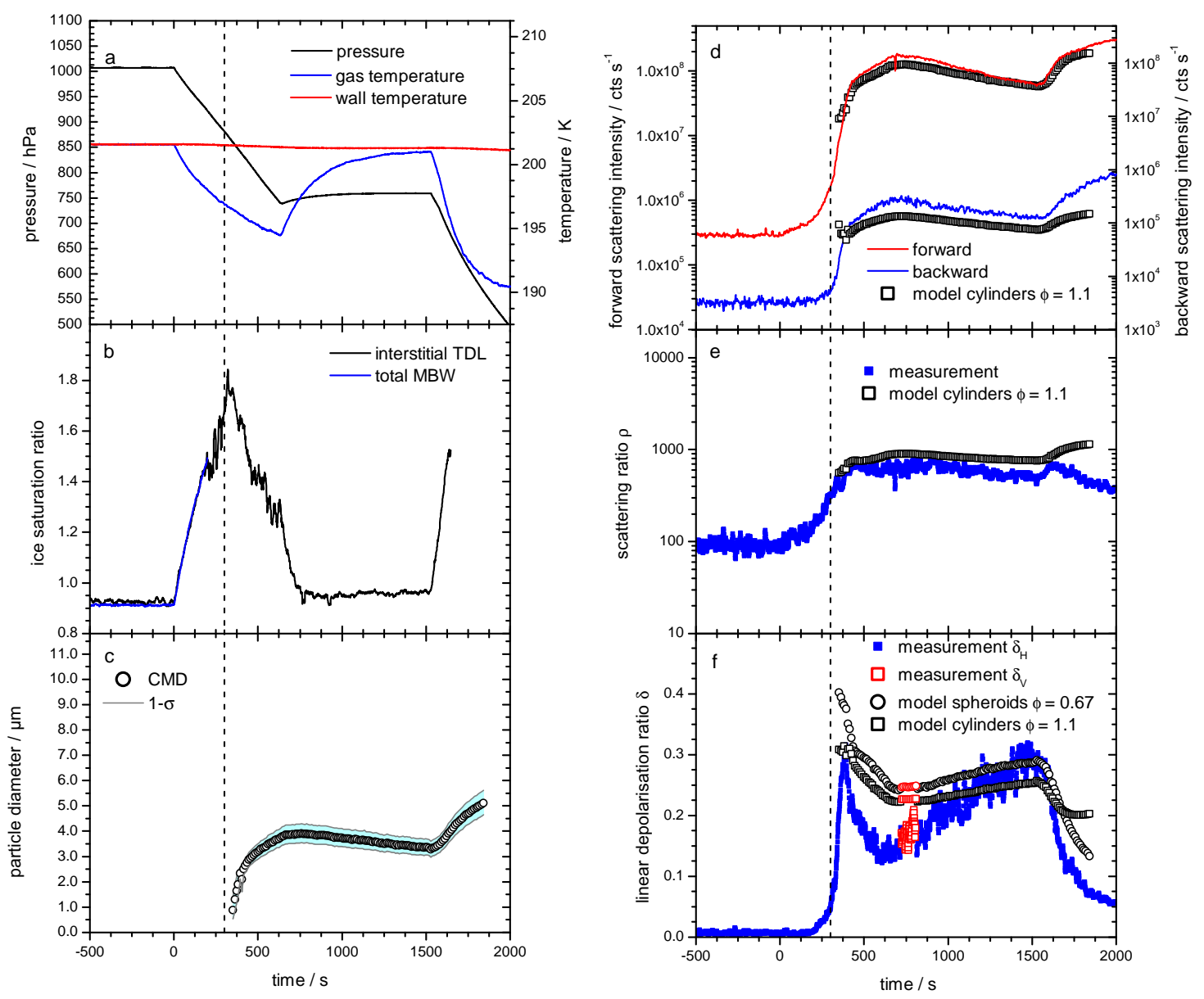

Fig. 9. Homogeneous ice nucleation experiment ICE01_14. The individual panels show the same measurements as in Fig. 6, with the exception of (b) that shows the evolution of the humidity as ice saturation ratio instead of relative humidity. The onset time of ice nucleation is indicated by the dashed vertical lines in the panels. The SIMONE measurement results depicted in (d-f) were modelled by T-matrix calculations for finite cylinders and spheroids. Note that the SID3 instrument was not available for this experiment. See text for details.

evolution of the count median equal-volume sphere diameter $\left(\overline{D_{\mathrm{v}}}\right)$ of the ice cloud particle ensemble retrieved from the measured FTIR extinction spectra. During the expansion cooling phase of the experiment, i.e. until $t=630 \mathrm{~s}$, the median particle diameter continuously increased to a maximum value of $\overline{D_{\mathrm{v}}}=4 \mu \mathrm{m}$. After the expansion had been stopped, the temperature difference between the chamber gas and the warmer chamber walls started to balance and the existing ice particle surface confined the water vapour saturation ratio to ice saturated conditions. With increasing gas temperature, the ice particles eventually started to sublimate which resulted in a gradual decrease of $\overline{D_{\mathrm{v}}}$ with time as depicted in Fig. 9c.

The sublimating ice particles were then forced to grow again by starting a second expansion cycle at $t=1530 \mathrm{~s}$ with a faster pumping speed of $90 \%$ of full capacity. At that time, the ice particle number concentration was already reduced to about $50 \mathrm{~cm}^{-3}$. The growing ice particles were observed for further $300 \mathrm{~s}$ by the FTIR and WELAS instruments. Unfortunately, the TDL interstitial water vapour measurement is not very stable at those low temperatures and high pumping speeds and, therefore, the data are disregarded for $t>1647 \mathrm{~s}$. Therefore, it is not clear whether the ice nucleation threshold was again reached within the subsequent $200 \mathrm{~s}$ observation time. However, there are no indications for a second ice nucleation event neither from the WELAS nor from the FTIR data and, thus, it is very likely that the growing ice particles effectively depleted the interstitial water vapour and confined the ice saturation ratio below the homogeneous nucleation threshold. A median equivalent diameter of $\overline{D_{\mathrm{v}}}=5 \mu \mathrm{m}$ had been reached by the growing ice particles before the FTIR measurement was stopped.

The SIMONE measurement data and the results of the Tmatrix calculations are depicted in Fig. 9d-f. The forward and backward scattering intensities in Fig. 9d show a rapid increase after the ice nucleation has been initiated, reflecting the fast growth of the ice particles during the initial growth phase when the saturation ratio was still high. For the remaining experiment time, the scattering signals nicely follow the 
trend of the retrieved median equivalent diameter $\overline{D_{\mathrm{v}}}$ shown in Fig. 9c, i.e. a moderate increase when the supersaturation was depleting, a moderate decrease during the sublimation period and a second rapid increase when the chamber was again expanded. For the period after the start of the expansion and before the ice nucleation has been initiated, the forward scattering intensity and the scattering ratio $\rho$ in Fig. 9e show a continuous but small increase due to the uptake of water vapour by the diluting $\mathrm{H}_{2} \mathrm{SO}_{4}$ solution droplets. The linear depolarisation ratio $\delta$ in Fig. 9f stays at its background value until ice starts to nucleate, followed by a strong increase to a peak value of $\delta=0.33$ at $t=393 \mathrm{~s}$. At this time, the ice crystals have grown to an equivalent diameter of $\overline{D_{\mathrm{v}}}=2.0 \mu \mathrm{m}$. During further growth of the ice particles until the expansion was stopped at $t=630 \mathrm{~s}$, the depolarisation ratio strongly decreases to a value of $\delta=0.13$ although the scattering intensities in Fig. 9d still increase and the scattering ratio in Fig. 9e stays rather constant. This is evidence for the strong non-linear size dependence of the linear deporisation ratio for small micrometer-sized ice crystals as it was theoretically predicted by Mishchenko and Sassen (1998). The subsequent behaviour of the depolarisation ratio during the sublimation and second growth phases, namely a continuous increase (decrease) with decreasing (increasing) particle size, is yet another observation of this non-linear size dependence.

The change of the incident laser polarisation to the perpendicular orientation between $t=725 \mathrm{~s}$ and $t=805 \mathrm{~s}$ has no effect on the measured depolarisation ratio (i.e. $\delta_{\mathrm{V}}=\delta_{\mathrm{H}}$, cf. the red open squares in Fig. 9f). As in the experiments with iron oxide particles presented in Sect. 4.2, this indicates that for the generated small ice particles the element $S_{12}$ of the Mueller matrix is already small for our detection angle of $178.2^{\circ}$. This is crucial for the atmospheric relevance of our data because for a small $S_{12}$ the SIMONE depolarisation ratio measured at $178.2^{\circ}$ will be close to the value at $180^{\circ}$, i.e. $\delta_{\text {lidar }}$ of Eq. (13), which is the detection angle of atmospheric lidar applications.

According to the procedure described in Sect. 3.2, the SIMONE measurement data were modelled by T-matrix calculations. In doing so, we made several runs using the same FTIR retrieved size distribution but assuming different particle habits (i.e. cylinders and spheroids) and aspect ratios $\phi$ in order to get the best match with the measured depolarisation data. These best match results are shown as black circles and squares in Fig. 9d-f. The modelled depolarisation ratios of prolate spheroids with $\phi=0.67$ and of compact cylinders with $\phi=1.1$, which are plotted in Fig. 9f, nicely mimic the trend of the measured depolarisation ratio. The absolute value of the measured depolarisation ratio, however, is not exactly reproduced over the whole experiment period which might be due to the simplified model assumptions, i.e. cylindrical and spheroidal particle shapes with fixed aspect ratios. Interestingly, we also observe the equivalence of $\delta_{\mathrm{V}}$ and $\delta_{\mathrm{H}}$ for the modelling results which seems to be a general feature of small ice particles.

Comparing the modelled scattering intensities of the ice cloud in Fig. 9d, we have applied the same prefactor and adjustment factor for the modelled intensities of the ice cloud that were deduced in the supercooled droplet experiment discussed in Sect. 4.1. Whereas the modelled forward scattering intensity matches the measurement data of Fig. 9d very well, the measured backward scattering signal is underestimated by the modelling result. Consequently, the modelled forward-to-backward scattering ratio shown in Fig. 9e overestimates the ratio deduced from the SIMONE measurements by up to about $50 \%$.

\subsubsection{Heterogeneous nucleation at $T_{\text {initial }}=204 \mathrm{~K}$ (HALO06_30)}

In contrast to the previous experiment where we used sulphuric acid solution droplets to nucleate ice homogeneously, we used soot particles from the graphite spark generator in experiment HALO06_30 to investigate heterogeneous ice nucleation. The experiment was conducted at a comparable initial temperature of $203.6 \mathrm{~K}$ and with an initial soot particle number concentration of about $490 \mathrm{~cm}^{-3}$. Figure 10 depicts the course of HALO06_30 in the same manner as presented in Fig. 9 for the sulphuric acid experiment ICE01_14.

In contrast to the homogeneous nucleation of ice, the soot aerosol initiated ice formation via heterogeneous nucleation in the deposition mode at a significantly lower supersaturation of only about $28 \%$ at $t=95 \mathrm{~s}$ experiment time. At the time of maximum saturation ratio, about 70 ice particles per $\mathrm{cm}^{3}$ had been nucleated which then grew to a volume equivalent diameter of $\overline{D_{\mathrm{v}}}=3.8 \mu \mathrm{m}$ until $t=500 \mathrm{~s}$ when the pumping speed was reduced. The correspondingly reduced cooling rate did not counterbalance the heat flux from the warmer chamber walls. Therefore, the chamber temperature gradually increased, resulting in a slow sublimation of the ice particles and a confinement of the saturation ratio to ice saturated conditions. The fact that the median volume equivalent diameter of the ice particle ensemble depicted in Fig. 10c was rather constant during this period indicates that the mass loss rate was indeed slow. This could be confirmed by an analysis of the ice water content that was deduced by two independent methods; the FTIR size distribution retrieval and the MBW-TDL closure. This analysis revealed a mass loss of only $9 \%$ between $t=600 \mathrm{~s}$ and $t=1200 \mathrm{~s}$. The mass loss rate by sublimation was increased after $t=1200 \mathrm{~s}$ when the gas in the chamber was compressed by a controlled flow of dry synthetic air into the volume. In this way, the ice cloud was subjected to a significant subsaturation with respect to ice of about 5 to $7 \%$, resulting in a complete sublimation of the ice particles within $900 \mathrm{~s}$.

As in Fig. 9, the scattering intensities measured during the growth, maintenance, and sublimation periods of the ice cloud are nicely mimicked by the model results assuming 

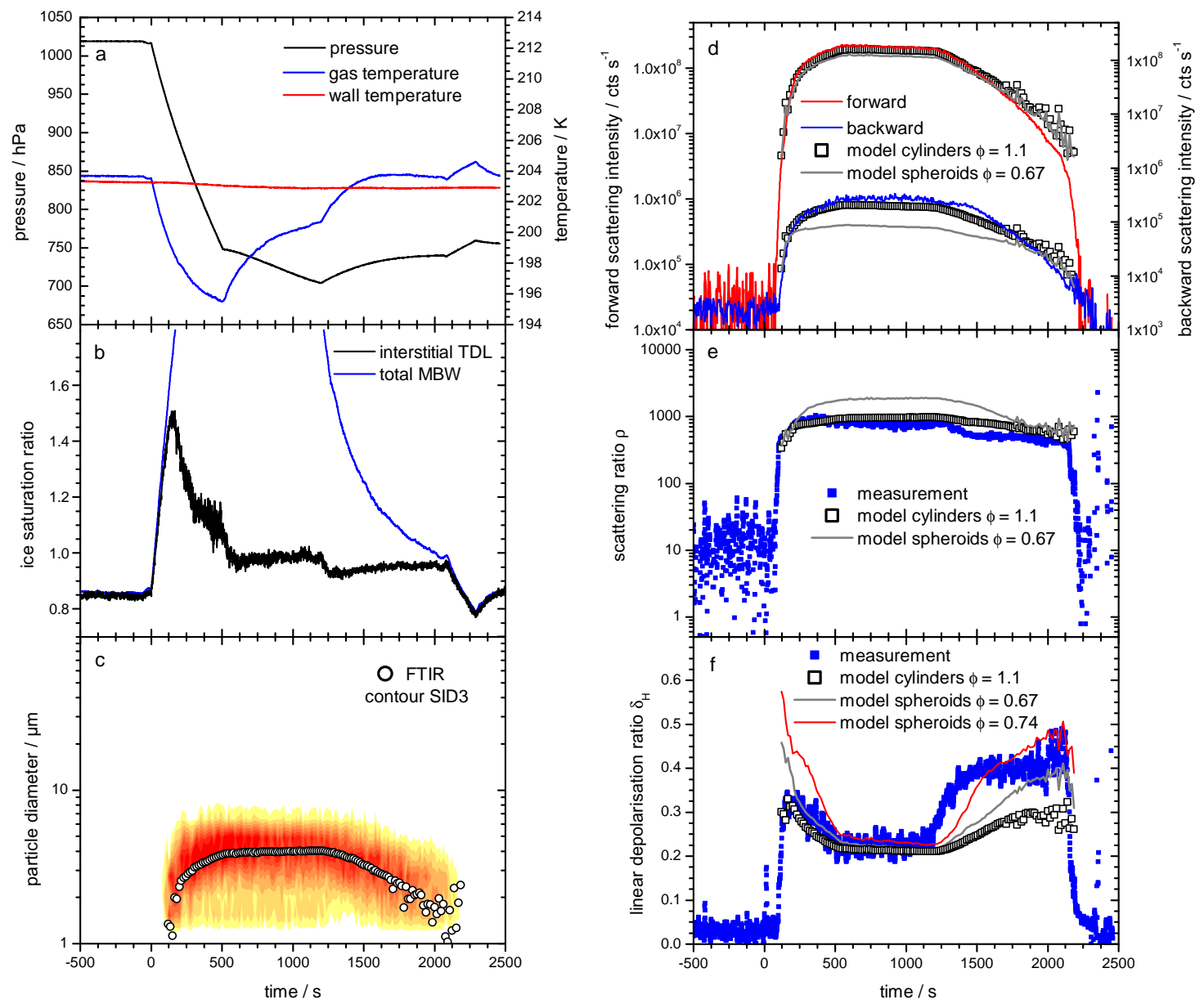

Fig. 10. As Fig. 9 but for the heterogeneous ice nucleation experiment HALO06_30.

oblate ice cylinders with an aspect ratio of 1.1 (Fig. 10d). Also in this experiment the forward scattering intensity is matched very well by the modelling result whereas the backscattering measurement is slightly underestimated. This discrepancy between the quality of the forward and backward simulations is even more pronounced for the modelling results for prolate spheroidal ice particles with an aspect ratio of 0.67 .

The measured depolarisation ratio $\delta_{\mathrm{H}}$, plotted in Fig. 10f, shows a similar size dependence as it was observed in the homogeneous ice nucleation experiment ICE01_14, namely a maximum value of 0.33 during the initial growth at a median diameter around $\overline{D_{\mathrm{v}}}=2.0 \mu \mathrm{m}$, a decrease to values around 0.22 during the remaining growth and stabilisation periods, and an increase to values around 0.4 during the final sublimation phase. The growth and stabilisation periods of the experiment, i.e. until $t=1200 \mathrm{~s}$, are excellently reproduced by the assumption of slightly oblate cylinders and prolate spheroids with $\phi=1.1$ and 0.67 , respectively. However, the rapid increase of the depolarisation ratio observed during the forced sublimation period is not as closely matched by these two particle models as the initial experimental phases. This indicates that a different particle shape has to be assumed for the sublimating ice crystals. A much better simulation of the temporal evolution of $\delta_{\mathrm{H}}$ during the sublimation period is achieved by assuming prolate spheroidal particles with a somewhat higher aspect ratio of 0.74 (shown as red line in Fig. 10f). As shown by Nelson (1998), spheroids are indeed a realistic proxy for sublimating ice particles.

\subsubsection{Heterogeneous nucleation at $T_{\text {initial }}=224 \mathrm{~K}$ (HALO06_25)}

The last experiment discussed here was again conducted with soot particles from the graphite spark generator but at a higher initial temperature of $224.3 \mathrm{~K}$ (Fig. 11). In contrast to HALO06_30 where the ice nucleation started at a supersaturation of about $28 \%$, an even lower supersaturation of only about $15 \%$ (reached at $t=40 \mathrm{~s}$ ) was sufficient to trigger ice nucleation in this experiment. An ice particle number concentration of $77 \mathrm{~cm}^{-3}$ was nucleated until the peak saturation ratio was reached. Due to the higher water vapour 

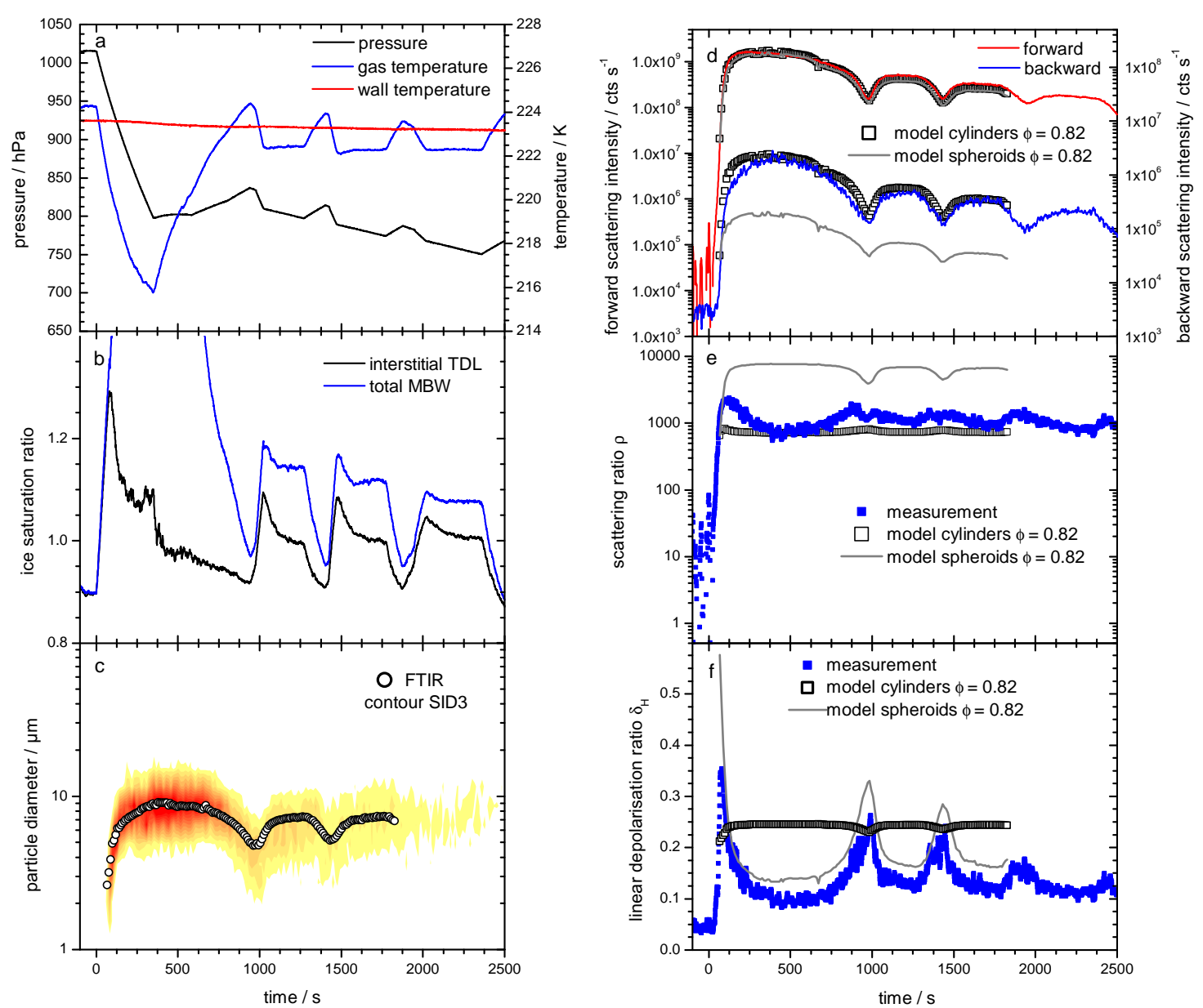

Fig. 11. As Figs. 9 and 10 but for the heterogeneous ice nucleation experiment HALO06_25 conducted at a higher temperature of $T_{\text {initial }}=$ 224.3 K. Note the larger sizes of the ice particles grown in this experiment compared to the experiments ICE01_14 and HALO06_30. Starting at about $t=500$ s experiment time, the ice cloud particles were repeatedly forced to sublimate and grow.

concentration available at warmer temperatures, the ice particle ensemble grew to a larger volume equivalent median diameter of about $\overline{D_{\mathrm{v}}}=9 \mu \mathrm{m}$ (compared to $\overline{D_{\mathrm{v}}}=3.8 \mu \mathrm{m}$ in HALO06_30) before the expansion was stopped at $t=350 \mathrm{~s}$. After a short maintenance period of about $150 \mathrm{~s}$, the ice cloud was forced to sublimate by the addition of a controlled flow of dry synthetic air resulting in a continuous decrease of $\overline{D_{\mathrm{v}}}$ (Fig. 11c). Before the ice cloud was completely sublimated, the ice particles were forced to grow again by starting another expansion cooling cycle at $t=960 \mathrm{~s}$ when the cloud was already subsaturated by about $9 \%$. At this time, the ice particle ensemble had been sublimated to an equivalent diameter of $\overline{D_{\mathrm{v}}}=4.8 \mu \mathrm{m}$ and a number concentration of about $22 \mathrm{~cm}^{-3}$. This second expansion cooling cycle was stopped at a supersaturation of $9 \%$, i.e. well below the nucleation threshold observed in the initial expansion. In this way, the formation of new ice particles by heterogeneous nucleation on the interstitial aerosol particles was avoided. As can be seen in Fig. 11, this procedure was repeated for another two times.

The growth and sublimation cycles are nicely reflected by the measured SIMONE scattering intensities depicted in Fig. 11d. As in the previous experiments, the measured scattering intensities can be reproduced by the T-matrix model assuming cylindrical ice particles, with a prolate aspect ratio of 0.82 in this case. The assumption of spheroidal ice particles, here with the same aspect ratio of 0.82 , again leads to significantly lower backscattering signals and, consequently, to an overestimation of the scattering ratio in Fig. 11e. However, the course of the measured depolarisation ratio depicted in Fig. 11f can only be reproduced by the spheroidal particle assumption. Such behaviour was not clearly observed in the previous experiments at colder temperatures except the very end of ICE01_14 (Fig. 9) when the ice particles grew to a median diameter slightly above $5 \mu \mathrm{m}$. A possible explanation for this discrepancy is given in the next section. 

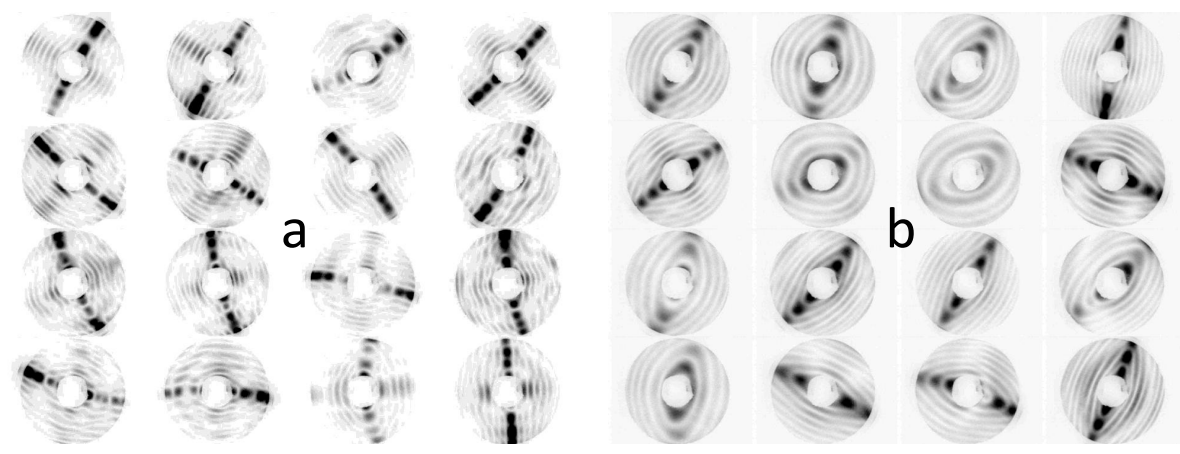

Fig. 12. Representative selection of SID 3 single particle scattering patterns recorded in HALO06_25 during a growth period (a) and a sublimation period (b). A statistical analysis of the images revealed that more than $60 \%$ of the ice particles had a columnar shape with a two-fold or four-fold symmetric pattern. The sublimation of ice particles results in roundish particle shapes inducing oval scattering patterns (b).

We now give an example of SID3 measurements to demonstrate that the spheroidal particle shape is a realistic assumption for sublimating ice particles. The SID3 single particle scattering patterns of Fig. 12 clearly show a transition from the cross-like patterns observed during the ice particle growth and cloud maintenance periods to oval patterns observed during the sublimation periods. While the former indicate (hexagonal) columnar ice particles with sharp edges the latter clearly reflect columnar particles with rounded edges provoked by the faster sublimation near the edges of the ice facets (Nelson, 1998).

\section{Atmospheric implications}

The presented cirrus cloud simulation experiments show that high backscattering particle linear depolarisation ratios $\delta_{\mathrm{p}}$ are a common feature of small ice particles with sizes well below $10 \mu \mathrm{m}$. Since the SIMONE depolarisation measurement is roughly $2^{\circ}$ off the exact backscattering direction, we first have to quantify the differences between $\delta_{\text {SIMONE }}$ and $\delta_{\text {lidar }}$ expected in exact backscattering direction before we can discuss the implications for atmospheric lidar measurements. For this purpose, we used the Mueller matrix look-up tables to calculate the backscattering depolarisation ratios at $178^{\circ}$ and $180^{\circ}$ for randomly oriented spheroidal particle ensembles with different aspect ratios and size parameters at a fixed mode width of $\sigma_{\mathrm{g}}=1.2$. The results are depicted in Fig. 13. According to Eq. (13), atmospheric lidar depolarisation measurements $\delta_{\mathrm{p}}$ depend only on the ratio $S_{22} / S_{11}$ of the Mueller matrix. This ratio can be deduced from the SIMONE measurements of $\delta_{\mathrm{H}}$ and $\delta_{\mathrm{V}}$ by application of Eq. (14). The difference $\Delta \delta_{\mathrm{p}}$ between $\delta_{\mathrm{p}}$ at the SIMONE detection angle of $178^{\circ}$ and at the lidar angle of $180^{\circ}$ is plotted in the lower right panel of Fig. 13. According to this plot, SIMONE underestimates the lidar depolarisation ratio by less than 0.1 for small prolate and oblate ice particles. Moreover, the difference between $\delta_{\mathrm{V}}$ and $\delta_{\mathrm{H}}$ shown in the upper right panel is typically below 0.05 for size parameters below 20, but can be signif- icantly higher for larger size parameters and especially for particles that deviate only slightly from the spherical shape. This means that for small ice particles with sizes below about $3.1 \mu \mathrm{m}$, the SIMONE depolarisation ratios of Eqs. (11) and (12) are equal and representative for $\delta_{\text {lidar }}$ (with a maximum negative offset of 0.1 ) even without changing the incident laser polarisation direction.

Within these limitations, the SIMONE depolarisation data measured during the ice particle growth and sublimation phases of the above experiments are representative for $\delta_{\text {lidar }}$. Therefore, the high lidar depolarisation values above 0.4 that are observed in contrails and natural upper tropospheric cirrus clouds as reviewed in Sect. 1 might be indications for the presence of small micrometer-sized ice particles. Note that the maximum $\delta_{\mathrm{H}}$ ratios given in Table 1 have to be corrected by a positive offset of about 0.1 to estimate the lidar depolarisation ratio. The fact that we have measured strong depolarisation values especially in sublimating cold ice clouds (e.g. experiment HALO06_30, Fig. 10) could be of atmospheric relevance in the context of the detrainment of convective anvil clouds in the tropical tropopause layer (TTL). Recent analyses of satellite data show that at least $30 \%$ of cirrus in the TTL are of convective origin (Wang and Dessler, 2012). In situ measurements of the ice particle size distribution in the vicinity of and within the outflows of such convective systems clearly show that the ice particle sizes decrease with increasing altitude and decreasing temperature (Frey et al., 2011). In the TTL the number size distributions peak between 6 and $15 \mu \mathrm{m}$, and sometimes even a monotonic decrease of the number concentration with size was observed, indicating a maximum of the size distribution below $3 \mu \mathrm{m}$ (de Reus et al., 2009). Sublimation of larger ice particles was identified as a possible explanation for these very small particles. In conclusion, our experimental findings of high $\delta_{\mathrm{H}}$ values in case of small (sublimating) ice particles and the strong decrease of $\delta_{\mathrm{H}}$ with increasing particle size could serve as a link that connects the CALIOP $\delta_{\text {lidar }}$ observations in tropical ice clouds with the in situ microphysical measurements 

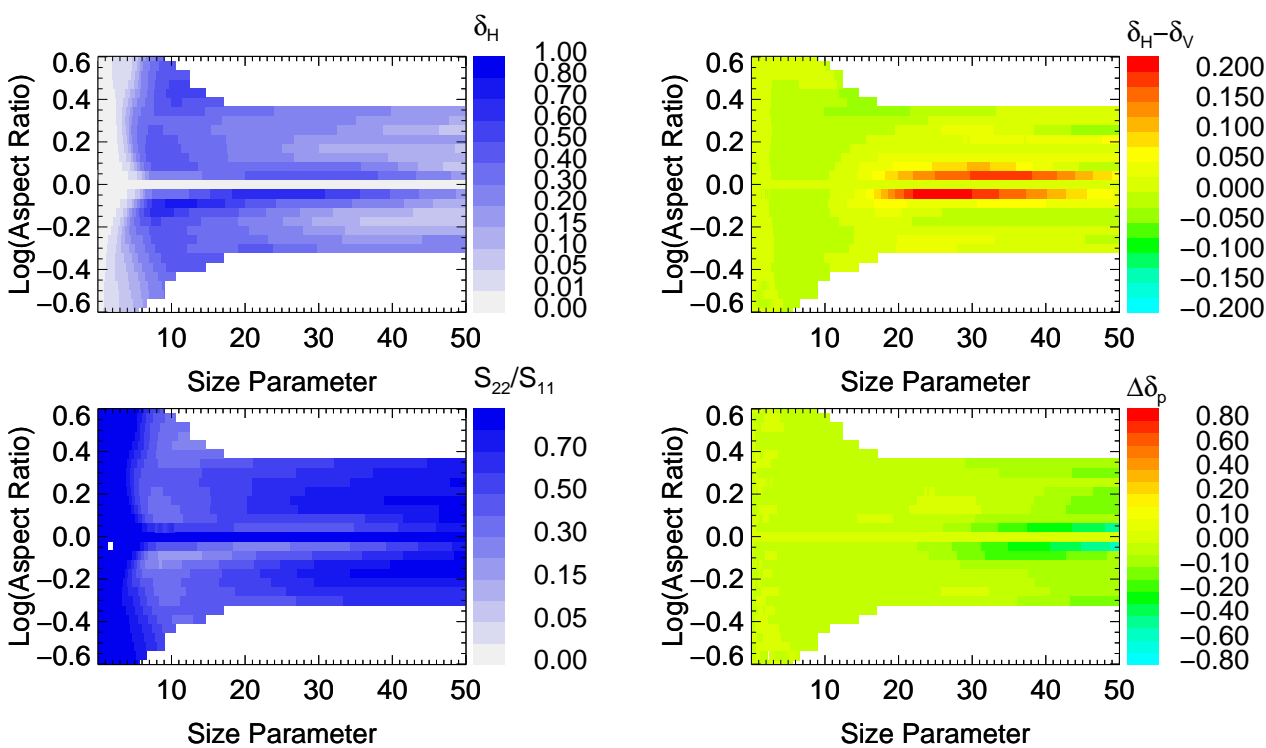

Fig. 13. Results of T-matrix calculations for spheroidal ice particles with different aspect ratios and size parameters. Upper left: linear depolarisation ratio $\delta_{\mathrm{H}}$ for a detection angle of $178^{\circ}$. Upper right: difference between the linear depolarisation ratios for parallel $(\mathrm{H})$ and perpendicular (V) incident laser polarisation. Lower left: normalised Mueller matrix element $S_{22} / S_{11}$ for a detection angle of $178^{\circ}$. Lower right: difference in $\delta_{\mathrm{p}}$ for the detection angles $178^{\circ}$ (SIMONE) and $180^{\circ}$ (lidar) using Eq. (13). Negative values indicate higher $\delta_{\mathrm{p}}$ ratios at $180^{\circ}$.

of convective outflows in the TTL. However, further in situ investigations aiming at assessing the prevalence of small ice particles in upper tropospheric cirrus clouds and discriminating sublimating ice particles are necessary to substantiate this link.

At this point, we want to briefly note that in contrast to the presented chamber experiments large ice crystals often coexist with small ice particles in cirrus clouds. According to our chamber studies with large ice crystals (Amsler et al., 2009; Schön et al., 2011; Abdelmonem et al., 2011), these particles show a broad range of $\delta_{\mathrm{H}}$ values from 0.04 to 0.4 depending on the particle size and shape. Therefore, the depolarization from small cirrus ice particles might be significantly masked by the presence of a few large ice particles.

Another relevant finding of our study is the applicability of the T-matrix model for prolate spheroidal particles (and partly also for slightly oblate cylindrical particles) for modelling the depolarisation ratio of cold ice clouds composed of small micrometer-sized ice crystals. The T-matrix method was previously proposed as a useful tool for interpreting lidar depolarisation data measured in contrails (Mishchenko and Sassen, 1998). Especially the predicted strong decrease of $\delta_{\text {lidar }}$ with a gradual increase of the particle size from about 2 to $4 \mu \mathrm{m}$ was nicely confirmed by our experiments. Interestingly, the measured depolarisation ratios could be mimicked by assuming a single shape for the ice particle ensemble, whose total ice volume and number size distribution was constrained by FTIR spectroscopy and SID3 particle sizing. Yet, the use of a shape distribution, as constrained from e.g. SID3 single particle measurements, will likely further improve the fit result. In contrast to this finding, the backscattering intensity was always underestimated when assuming spheroidal particles and could only be matched assuming cylindrical particles. This finding highlights the importance of retroreflections at rectangular crystal troughs for the backscattering intensity (Macke and Mishchenko, 1996) also in case of small ice crystals. The fact that the modelled forward scattering intensity was almost independent on the assumed particle shape shows that small angle light scattering is dominated by diffraction. Based on these results, it can be speculated that an optical particle model assuming a size and shape distribution of hexagonal ice particles is necessary in order to match both the observed depolarisation ratios and the scattering intensities at the same time.

\section{Conclusion and outlook}

The main purpose of this work was to introduce the laser scattering and depolarisation instrument SIMONE which is in routine operation at the large aerosol and cloud simulation chamber AIDA. The detection concept of the instrument closely resembles that of polarisation lidar instruments which are widely used for remote sensing of atmospheric aerosols and clouds by the analysis of backscattered laser radiation. In addition to the near-backscattering channel, the SIMONE setup also comprises a near-forward scattering channel, which was proven to be very sensitive to the size distribution of the particle ensemble under consideration. A specific 
focus of the work was to evaluate the capabilities of the instrument for measuring the backscattering particle linear depolarisation ratios $\delta_{\mathrm{H}}$ and $\delta_{\mathrm{V}}$ of artificially generated cold ice clouds that might closely resemble those in contrails and natural cirrus. In addition to the SIMONE measurements, the ice clouds were also probed by in situ FTIR extinction spectroscopy and the single particle optical detectors WELAS and SID3.

Ice clouds generated in AIDA below $225 \mathrm{~K}$ are typically composed of small ice particles with equivalent diameters significantly below $20 \mu \mathrm{m}$. The experiments presented in this work clearly showed that these ice clouds induce a strong backscattering linear depolarisation signal especially during the initial growth and final sublimation periods. It could be shown that these findings are consistent with the results of T-matrix calculations for spheroidal and cylindrical particles. In this way, the T-matrix method has proven as a valuable tool for interpreting lidar depolarisation data measured in contrails and young cirrus as previously proposed by Mishchenko and Sassen (1998). Further implications for the interpretation of the strong depolarisation ratios recently observed in tropical ice clouds by the CALIOP spaceborne instrument are possible (Martins et al., 2011). In particular, the high depolarisation ratios observed by SIMONE in sublimating ice clouds might be of atmospheric relevance in the context of deep convective detrainment processes in the TTL.

Sublimation of ice clouds at cold temperatures and its impact on the microphysical and optical properties of the ice crystals will be the subject of forthcoming chamber studies. The SID3 scattering patterns will be analysed in a way to deduce reliable shape distributions of the generated ice particle ensembles. It is envisaged to use these shape distributions in modeling studies with the finite-difference timedomain (FDTD) method. This method allows the calculation of the scattering properties of hexagonal ice columns which is likely the better ice particle model that simultaneously represents the backscattering intensity as well as the linear depolarisation ratio.

Acknowledgements. The authors are grateful to all members of the AIDA staff for their continuous support during the chamber experiments. Steffen Vogt is thanked for the mechanical design of the SIMONE setup. The work has been funded by the Deutsche Forschungsgemeinschaft within the HALO priority program 1294 (DFG contracts SCHN 1140/1-2 and MOEH 668/1-2) and the Helmholtz-Gemeinschaft Deutscher Forschungszentren as part of the program "Atmosphere and Climate". We acknowledge support by Deutsche Forschungsgemeinschaft and Open Access Publishing Fund of Karlsruhe Institute of Technology.
The service charges for this open access publication have been covered by a Research Centre of the Helmholtz Association.

Edited by: D. Baumgardner

\section{References}

Abdelmonem, A., Schnaiter, M., Amsler, P., Hesse, E., Meyer, J., and Leisner, T.: First correlated measurements of the shape and light scattering properties of cloud particles using the new Particle Habit Imaging and Polar Scattering (PHIPS) probe, Atmos. Meas. Tech., 4, 2125-2142, doi:10.5194/amt-4-2125-2011, 2011.

Amsler, P., Stetzer, O., Schnaiter, M., Hesse, E., Benz, S., Möhler, O., and Lohmann, U.: Ice crystal habits from cloud chamber studies obtained by in-line holographic microscopy related to depolarization measurements, Appl. Optics, 48, 58115822, 2009.

Benz, S., Megahed, K., Möhler, O., Saathoff, H., Wagner, R., and Schurath, U.: $T$-dependent rate measurements of homogeneous ice nucleation in cloud droplets using a large atmospheric simulation chamber, J. Photoch. Photobio. A, 176, 208-217, 2005.

Burkhardt, U. and Kärcher, B.: Global radiative forcing from contrail cirrus, Nat. Clim. Change, 1, 54-58, 2011.

Cooper, S. J. and Garrett, T. J.: Identification of small ice cloud particles using passive radiometric observations, J. Appl. Meteorol. Climatol., 49, 2334-2347, 2010.

Cooper, S. J. and Garrett, T. J.: Application of infrared remote sensing to constrain in-situ estimates of ice crystal particle size during SPartICus, Atmos. Meas. Tech., 4, 1593-1602, doi:10.5194/amt4-1593-2011, 2011.

Cotton, R. J., Benz, S., Field, P. R., Möhler, O., and Schnaiter, M.: Technical Note: A numerical test-bed for detailed ice nucleation studies in the AIDA cloud simulation chamber, Atmos. Chem. Phys., 7, 243-256, doi:10.5194/acp-7-243-2007, 2007.

de Reus, M., Borrmann, S., Bansemer, A., Heymsfield, A. J., Weigel, R., Schiller, C., Mitev, V., Frey, W., Kunkel, D., Kürten, A., Curtius, J., Sitnikov, N. M., Ulanovsky, A., and Ravegnani, F.: Evidence for ice particles in the tropical stratosphere from in-situ measurements, Atmos. Chem. Phys., 9, 6775-6792, doi:10.5194/acp-9-6775-2009, 2009.

Del Guasta, M. and Niranjan, K.: Observation of low-depolarization contrails at Florence (Italy) using a $532-1064 \mathrm{~nm}$ polarization lidar, Geophys. Res. Lett., 28, 4067-4070, 2001.

Field, P. R., Heymsfield, A. J., and Bansemer, A.: Shattering and particle interarrival times measured by optical array probes in ice clouds, J. Atmos. Ocean. Technol., 23, 1357-1371, 2006.

Freudenthaler, V., Homburg, F., and Jäger, H.: Optical parameters of contrails from lidar measurements: linear depolarization, Geophys. Res. Lett., 23, 3715-3718, 1996.

Frey, W., Borrmann, S., Kunkel, D., Weigel, R., de Reus, M., Schlager, H., Roiger, A., Voigt, C., Hoor, P., Curtius, J., Krämer, M., Schiller, C., Volk, C. M., Homan, C. D., Fierli, F., Di Donfrancesco, G., Ulanovsky, A., Ravegnani, F., Sitnikov, N. M., Viciani, S., D’Amato, F., Shur, G. N., Belyaev, G. V., Law, K. S., and Cairo, F.: In situ measurements of tropical cloud properties in the West African Monsoon: upper tropospheric ice clouds, Mesoscale Convective System outflow, and subvisual cirrus, At- 
mos. Chem. Phys., 11, 5569-5590, doi:10.5194/acp-11-55692011, 2011.

Garrett, T. J., Gerber, H., Baumgardner, D. G., Twohy, C. H., and Weinstock, E. M.: Small, highly reflective ice crystals in low-latitude cirrus, Geophys. Res. Lett., 30, 2132, doi:10.1029/2003GL018153, 2003.

Haner, D. A., McGuckin, B. T., and Bruegge, C. J.: Polarization characteristics of Spectralon illuminated by coherent light, Appl. Optics, 38, 6350-6356, 1999.

Hare, D. E. and Sorensen, C. M.: The density of supercooled water - 2. bulk samples cooled to the homogeneous nucleation limit, J. Chem. Phys., 87, 4840-4845, 1987.

Jensen, E. J., Lawson, P., Baker, B., Pilson, B., Mo, Q., Heymsfield, A. J., Bansemer, A., Bui, T. P., McGill, M., Hlavka, D., Heymsfield, G., Platnick, S., Arnold, G. T., and Tanelli, S.: On the importance of small ice crystals in tropical anvil cirrus, Atmos. Chem. Phys., 9, 5519-5537, doi:10.5194/acp-9-5519-2009, 2009

Kaye, P. H., Hirst, E., Greenaway, R. S., Ulanowski, Z., Hesse, E., DeMott, P. J., Saunders, C., and Connolly, P.: Classifying atmospheric ice crystals by spatial light scattering, Opt. Lett., 33, 1545-1547, 2008.

Korolev, A. V., Emery, E. F., Strapp, J. W., Cober, S. G., Isaac, G. A., Wasey, M., and Marcotte, D.: Small ice particles in tropospheric clouds: fact or artifact? Airborne Icing Instrumentation Evaluation Experiment, B. Am. Meteorol. Soc., 92, 967-973, 2011.

Langford, A. O., Portmann, R. W., Daniel, J. S., Miller, H. L., Eubank, C. S., Solomon, S., and Dutton, E. G.: Retrieval of ice crystal effective diameters from ground-based near-infrared spectra of optically thin cirrus, J. Geophys. Res.-Atmos., 110, D22201, doi:10.1029/2005jd005761, 2005.

Lawson, R. P.: Effects of ice particles shattering on the 2D-S probe, Atmos. Meas. Tech., 4, 1361-1381, doi:10.5194/amt-4-13612011, 2011.

Macke, A. and Mishchenko, M. I.: Applicability of regular particle shapes in light scattering calculations for atmospheric ice particles, Appl. Optics, 35, 4291-4296, 1996.

Mannstein, H. and Schumann, U.: Aircraft induced contrail cirrus over Europe, Meteorol. Z., 14, 549-554, 2005.

Martins, E., Noel, V., and Chepfer, H.: Properties of cirrus and subvisible cirrus from nighttime Cloud-Aerosol lidar with Orthogonal Polarization (CALIOP), related to atmospheric dynamics and water vapor, J. Geophys. Res.-Atmos., 116, D02208, doi:10.1029/2010JD014519, 2011.

McFarquhar, G. M., Um, J., Freer, M., Baumgardner, D., Kok, G. L., and Mace, G.: Importance of small ice crystals to cirrus properties: Observations from the Tropical Warm Pool International Cloud Experiment (TWP-ICE), Geophys. Res. Lett., 34, L13803, doi:10.1029/2007GL029865, 2007.

Mishchenko, M. I.: Light-scattering by size shape distributions of randomly oriented axially-symmetrical particles of a size comparable to a wavelength, Appl. Optics, 32, 4652-4666, 1993.

Mishchenko, M. I.: Electromagnetic scattering by nonspherical particles: a tutorial review, J. Quant. Spectrosc. Ra., 110, 808-832, 2009

Mishchenko, M. I. and Sassen, K.: Depolarization of lidar returns by small ice crystals: an application to contrails, Geophys. Res. Lett., 25, 309-312, 1998.
Mishchenko, M. I. and Travis, L. D.: Capabilities and limitations of a current FORTRAN implementation of the T-matrix method for randomly oriented, rotationally symmetric scatterers, J. Quant. Spectrosc. Ra., 60, 309-324, 1998.

Mishchenko, M. I., Travis, L. D., and Mackowski, D. W.: T-matrix computations of light scattering by nonspherical particles: a review, J. Quant. Spectrosc. Ra., 55, 535-575, 1996.

Möhler, O., Stetzer, O., Schaefers, S., Linke, C., Schnaiter, M., Tiede, R., Saathoff, H., Krämer, M., Mangold, A., Budz, P., Zink, P., Schreiner, J., Mauersberger, K., Haag, W., Kärcher, B., and Schurath, U.: Experimental investigation of homogeneous freezing of sulphuric acid particles in the aerosol chamber AIDA, Atmos. Chem. Phys., 3, 211-223, doi:10.5194/acp-3-211-2003, 2003.

Möhler, O., Büttner, S., Linke, C., Schnaiter, M., Saathoff, H., Stetzer, O., Wagner, R., Krämer, M., Mangold, A., Ebert, V., and Schurath, U.: Effect of sulfuric acid coating on heterogeneous ice nucleation by soot aerosol particles, J. Geophys. Res.-Atmos., 110, D11210, doi:10.1029/2004jd005169, 2005.

Morales, M. P., Gonzalezcarreno, T., and Serna, C. J.: The formation of alpha- $\mathrm{Fe}_{2} \mathrm{O}_{3}$ monodispersed particles in solution, J. Mater. Res., 7, 2538-2545, 1992.

Nelson, J.: Sublimation of ice crystals, J. Atmos. Sci., 55, 910-919, 1998.

Ocana, M., Morales, M. P., and Serna, C. J.: The growth-mechanism of alpha- $\mathrm{Fe}_{2} \mathrm{O}_{3}$ ellipsoidal particles in solution, J. Colloid Interf. Sci., 171, 85-91, 1995.

Ozaki, M., Kratohvil, S., and Matijevic, E.: Formation of monodispersed spindle-type hematite particles, J. Colloid Interf. Sci., 102, 146-151, 1984.

Querry, M. R.: Optical Constants of Minerals and Other Materials from the Millimeter to the UV, Rep. CRDEC-CR-88009, US Army, Aberdeen, MD, 1987.

Sassen, K. and Hsueh, C. Y.: Contrail properties derived from highresolution polarization lidar studies during SUCCESS, Geophys. Res. Lett., 25, 1165-1168, 1998.

Sassen, K. and Zhu, J.: A global survey of CALIPSO linear depolarization ratios in ice clouds: initial findings, J. Geophys. Res.Atmos., 114, D00h07, doi:10.1029/2009jd012279, 2009.

Saunders, R. W., Möhler, O., Schnaiter, M., Benz, S., Wagner, R., Saathoff, H., Connolly, P. J., Burgess, R., Murray, B. J., Gallagher, M., Wills, R., and Plane, J. M. C.: An aerosol chamber investigation of the heterogeneous ice nucleating potential of refractory nanoparticles, Atmos. Chem. Phys., 10, 1227-1247, doi:10.5194/acp-10-1227-2010, 2010.

Schön, R., Schnaiter, M., Ulanowski, Z., Schmitt, C., Benz, S., Möhler, O., Vogt, S., Wagner, R., and Schurath, U.: Particle habit imaging using incoherent light: a first step toward a novel instrument for cloud microphysics, J. Atmos. Ocean. Technol., 28, 493-512, 2011.

Schröder, F., Kärcher, B., Duroure, C., Ström, J., Petzold, A., Gayet, J. F., Strauss, B., Wendling, P., and Borrmann, S.: On the transition of contrails into cirrus clouds, J. Atmos. Sci., 57, 464480, 2000.

Segelstein, D.: The Complex Refractive Index of Water, PhD thesis, Kansas City, University of Missouri-Kansas City, 1981.

Steinke, I., Möhler, O., Kiselev, A., Niemand, M., Saathoff, H., Schnaiter, M., Skrotzki, J., Hoose, C., and Leisner, T.: Ice nucleation properties of fine ash particles from the Eyjafjallajökull 
eruption in April 2010, Atmos. Chem. Phys., 11, 12945-12958, doi:10.5194/acp-11-12945-2011, 2011.

Sussmann, R.: Vertical dispersion of an aircraft wake: Aerosol-lidar analysis of entrainment and detrainment in the vortex regime, J. Geophys. Res.-Atmos., 104, 2117-2129, 1999.

Takano, Y. and Jayaweera, K.: Scattering phase matrix for hexagonal ice crystals computed from ray optics, Appl. Optics, 24, 3254-3263, 1985.

van de Hulst, H.: Light Scattering by Small Particles, Dover Publications Inc., New York, 1981.

Voigt, C., Schumann, U., Jurkat, T., Schäuble, D., Schlager, H., Petzold, A., Gayet, J.-F., Krämer, M., Schneider, J., Borrmann, S., Schmale, J., Jessberger, P., Hamburger, T., Lichtenstern, M., Scheibe, M., Gourbeyre, C., Meyer, J., Kübbeler, M., Frey, W., Kalesse, H., Butler, T., Lawrence, M. G., Holzäpfel, F., Arnold, F., Wendisch, M., Döpelheuer, A., Gottschaldt, K., Baumann, R., Zöger, M., Sölch, I., Rautenhaus, M., and Dörnbrack, A.: In-situ observations of young contrails - overview and selected results from the CONCERT campaign, Atmos. Chem. Phys., 10, 90399056, doi:10.5194/acp-10-9039-2010, 2010.

Wagner, R., Benz, S., Möhler, O., Saathoff, H., Schnaiter, M., and Schurath, U.: Mid-infrared extinction spectra and optical constants of supercooled water droplets, J. Phys. Chem. A, 109, 7099-7112, 2005.

Wagner, R., Benz, S., Möhler, O., Saathoff, H., and Schurath, U.: Probing ice clouds by broadband mid-infrared extinction spectroscopy: case studies from ice nucleation experiments in the AIDA aerosol and cloud chamber, Atmos. Chem. Phys., 6, 47754800, doi:10.5194/acp-6-4775-2006, 2006.
Wagner, R., Benz, S., Möhler, O., Saathoff, H., Schnaiter, M., and Leisner, T.: Influence of particle aspect ratio on the midinfrared extinction spectra of wavelength-sized ice crystals, J. Phys. Chem. A, 111, 13003-13022, 2007.

Wagner, R., Benz, S., Bunz, H., Möhler, O., Saathoff, H., Schnaiter, M., Leisner, T., and Ebert, V.: Infrared optical constants of highly diluted sulfuric acid solution droplets at cirrus temperatures, J. Phys. Chem. A, 112, 11661-11676, 2008.

Wagner, R., Linke, C., Naumann, K. H., Schnaiter, M., Vragel, M., Gangl, M., and Horvath, H.: A review of optical measurements at the aerosol and cloud chamber AIDA, J. Quant. Spectrosc. Ra., 110, 930-949, 2009.

Wagner, R., Möhler, O., Saathoff, H., Schnaiter, M., and Leisner, T.: High variability of the heterogeneous ice nucleation potential of oxalic acid dihydrate and sodium oxalate, Atmos. Chem. Phys., 10, 7617-7641, doi:10.5194/acp-10-7617-2010, 2010.

Wagner, R., Möhler, O., Saathoff, H., Schnaiter, M., and Leisner, T.: New cloud chamber experiments on the heterogeneous ice nucleation ability of oxalic acid in the immersion mode, Atmos. Chem. Phys., 11, 2083-2110, doi:10.5194/acp-11-2083-2011, 2011.

Wang, T. and Dessler, A. E.: Analysis of cirrus in the tropical tropopause layer from CALIPSO and MLS data: a water perspective, J. Geophys. Res., 117, D04211, doi:10.1029/2011jd016442, 2012.

Zelenyuk, A. and Imre, D.: On the effect of particle alignment in the DMA, Aerosol Sci. Technol., 41, 112-124, 2007. 